\title{
Fundamentos, contenido y derecho comparado de la función de control interno en las entidades locales
}

\author{
José P. Viñas Bosquet \\ Interventor-Tesorero de Administración Local \\ Auditor-Doctor en Contabilidad y Finanzas
}

\begin{abstract}
Sumario: I. INTRODUCCIÓN. II. EL CONTROL INTERNO EN LAS ENTIDADES LOCALES. DEFINICIONES. III. EL CONTROL INTERNO COMO HERRAMIENTA PARA EL LOGRO DE OBJETIVOS. III.1. Objetivo democrático de la rendición de cuentas en los entes locales. III.2. Objetivos Presupuestarios y de Estabilidad Económica. III.2.A. Macroeconómicos y de Estabilidad. III.2.B. El control Microeconómico de la gestión presupuestaria. III.3. Objetivos Constitucionales y Legales. IV. NATURALEZA DEL CONTROL INTERNO. EL INFORME COSO. V. ASPECTOS CRÍTICOS DEL CONTROL INTERNO LOCAL EN LA ACTUALIDAD. V.I. Estatuto de funciones. V.2. Garantías para su ejercicio. VI. EL CONTROL INTERNO EN EL DERECHO LOCAL EUROPEO. VI.1. El sistema de control local de Inglaterra y Gales. VI.2. El sistema de contol de la gestión local en Francia. VI.3. Controles locales internos en Italia. VI.4. La Federación alemana y el control de las Entidades Locales. VII. RECAPITULACIÓN Y CONCLUSIONES. VIII. BIBLIOGRAFÍA.
\end{abstract}

\section{INTRODUCCIÓN}

La cada vez mayor complejidad en las que se desenvuelven las entidades locales y los gobiernos territoriales en casi todos los países Europeos, hace que los parlamentos y gobiernos nacionales, y los propios organismos de la Unión Europea, estén cada vez más interesados y activos, en la búsqueda e investigación de las medidas y regulaciones que sean necesarias, para lograr la adaptación permanente de los servicios locales, a los fines para los que han sido ideados, intentando con ello, una mejora de su nivel de calidad, así como una disminución del coste impositivo, que se deba soportar por los mismos.

La naturaleza de la administración local y de los servicios que presta, poseen unas peculiaridades propias, por cuanto en su gestión influyen factores técnicos, por la dificultad de medición de los servicios que se realizan, como de calidad del resultado, al ser poco útil la valoración del beneficio como síntesis de los mismos; como por otra parte, dentro de esa naturaleza de lo público, mencionar los factores de conducta o comportamiento en la gestión pública, del componente directivo-político, con una necesidad de reelección de los cargos, que incentiva la valoración del corto plazo en la toma de decisiones y en donde, la presión externa que genera tanto la prensa, como los grupos de presión, entorpecen y dificul- 
tan la racionalidad de las mismas; motivo por el cual, el análisis cuantitativo en la gestión pública, esta hoy tan retrasado, al menos en España; pero también por las grandes trabas que en este aspecto de la toma de decisiones, presentan para la mejora, pues la mayoría de los servicios locales, no se pueden inspeccionar previamente, ni se almacenan, no es fácil medir su calidad y además, utilizan de forma intensiva en su producción, una gran cantidad de mano de obra.

En este contexto administrativo, los mecanismos de control sobre la gestión de dichos servicios locales, deben de tomar una mayor importancia, si bien, como parte de la doctrina ya ha apuntado ${ }^{1}$, hasta ahora, dicha actividad de control, ha sido paulatinamente debilitada, cuando entendemos por nuestra parte, que deberían haberse potenciado, en una relación inversa, dado, que si existe una mayor autonomía en el ámbito de la gestión y decisión local, y esta debe realizarse de manera responsable ${ }^{2}$, parece lógico que de dicha gestión, deba comprobarse y ajustarse periódicamente a la vista de los efectos que produce, para lo cual, deberían aumentarse los instrumentos de información, revisión y control, que retroalimenten e informen de los resultados, y no como ha ocurrido, que se han ido disolviendo y debilitando, en un proceso permanente de socialización de los errores y equívocos, que hasta la fecha no ha sido resuelto.

$\mathrm{Al}$ introducirse en el estudio del control interno local, y dada la especial naturaleza que presenta la gestión de los servicios públicos locales, en primer lugar considero que debe analizarse, la relación existente entre la función de control y la actividad de gestión de la entidad, ya sea esta puramente local, ya vengan diseñada a través de competencias cedidas o compartidas con otras administraciones. Para lo cual, se analiza en primer lugar algunos de sus fundamentos, como herramienta para el logro de unos objetivos concretos en los entes locales, objetivos de control, actualmente puestos de relieve, por la nueva LGP, de 26 de Noviembre del 2003, y que nos dan paso, para profundizar en el estudio del contenido y características del mismo, realizando incluso una comparación con las aportaciones más recientes del mundo anglosajón, como es el informe

\footnotetext{
${ }^{1}$ Por citar los más conocidos: V. ARNAU BerniA, en relación a las debilidades del control sobre el endeudamiento local vide Rev. de Hacienda Local, n. ${ }^{\circ}$ 81. Sept-Dic. 1997, pp. 656 y ss. Sobre el atraso de la gestión pública, Anthony \& Young, «Management control in nonprofit organizations». Irwin-Mcgrawhill. Boston.1999.

${ }^{2}$ No en vano define el art. 3 de la Carta Europea de la Autonomía Local, que por autonomía local
se entiende el derecho y la capacidad (Ability) de las entidades locales, de ordenar y gestionar,
(Regulate and manage) una parte importante de los asuntos públicos, dentro de la ley, bajo su res-
ponsabilidad y en interés de sus vecinos.
} 
COSO, y en donde veremos, que la actual regulación legal española, presenta ciertas limitaciones, con unos efectos de debilidad y desajuste claro. Como apoyo a las conclusiones, el trabajo termina con una breve perspectiva comparada, de la regulación y modelos de estatutos del personal de control local, en otros países Europeos.

\section{EL CONTROL INTERNO EN LAS ENTIDADES LOCALES}

Dependiendo del campo concreto en el que nos movamos, el concepto de control interno, ha tenido y tiene diversas, acepciones y no todas ellas, de significado unívoco, dado que como comentan la mayoría de los tratadistas, hasta hoy no se ha desarrollado una teoría completa, sobre el control en las Administraciones Públicas y mucho menos, en lo referente al apartado del control interno, donde existe cierta confusión, dado que tradicionalmente se ha homologado esta idea, con fiscalización, revisión, supervisión, función interventora, etc., es decir, como una verificación ejercida por órganos dentro de la entidad, lo que si cabe en el campo local, es todavía más problemático, por ello las aportaciones científicas más divulgadas sobre dicha cuestión, las resumimos hoy, en los tres grupos siguientes:

$1^{\circ}$. Dentro de la teoría general y la ciencia de las Organizaciones, definen el control KoONTZ, O,DONNELl y WeIHRIH ${ }^{3}$ como la función administrativa dentro de la organización, que consiste en la medición y corrección en el desempeño, con objeto de asegurar que se están cumpliendo, tanto los objetivos de la entidad, como los planes para lograrlos. El presupuesto es por antonomasia, el instrumento financiero primario para la gestión, pero de manera inseparable también para el control, en las organizaciones y entidades complejas. Otros importantes autores de la Teoría de la Administración, han definido el control interno, como «Conjunto de normas y procedimientos encaminados a lograr la máxima eficacia en la gestión y en la protección de sus activos y patrimonio, así como, en la vigilancia para el cumplimiento de las normas» ${ }^{4}$.

$2^{\circ}$. En el Derecho Financiero Público, Martínez Lago ${ }^{5}$, lo define, como el control que se despliega en el seno del aparato ejecutivo, realiza-

\footnotetext{
${ }^{3}$ Koontz, O’Donnell y Weirrich, «Elementos de Administración» Mcgraw-Hill. México 1989 pp. 507 y ss.

${ }^{4}$ R. Anthony \& A.Young, «Management control in Nonprofit Organizations», Irwing Magrawhill. 1999.

5 M. A. Martínez Lago, «Manual de Do Presupuestario». Ed. Colex. Madrid, 1992.
} 
do por la Intervención de la Administración correspondiente. Es por tanto, un control concomitante a la fase de ejecución presupuestaria y su objetivo prioritario, es la comprobación de la conformidad de los actos administrativos a la norma jurídica (Legalidad). Por su parte J. PASCUAL GARCíA ${ }^{6}$, entiende de forma más amplia la función de control, predicable tanto, si es ejercido de forma externa, como interna, puesto que supone la fijación de unos hechos, la valoración de los mismos, desde una perspectiva legal, por lo que a diferencia de los asesores, su función no es la de ilustrar a los gestores sobre cuestiones o aspectos jurídicos o de gestión; o decidir como en una sentencia, sobre el derecho aplicable a una cuestión controvertida, sino el garantizar la gestión regular de las finanzas públicas, tanto de comportamientos irregulares o ilegales, control de legalidad, como de comportamientos antieconómicos, control de eficacia y eficiencia.

En la actualidad la Ley 47/2003 de 26 de noviembre, por el que se desarrolla el régimen de control interno en la Ad. ${ }^{\circ}$ del Estado, que es su expresión más reciente, vemos que el control interno, es el que se realizará mediante el ejercicio de la función Interventora, la denominada función de control financiero, y la Auditoria pública de muy similar definición a la contenida en la Ley Reguladora de las Haciendas Locales. Siendo la primera función, la que tiene por objeto controlar, que todos los actos de la Administración del Estado, de contenido económico y los ingresos y pagos que se deriven de ellos, se ajusten a las disposiciones aplicables al caso, y la segunda, el control financiero, comprenderá la verificación de forma continua de la situación económico financiera de las entidades del sector público, para comprobar el cumplimiento de la normativa, el adecuado registro y contabilidad de la totalidad de las operaciones realizadas y su fiel reflejo en las cuentas y estados contables, y en general que su gestión se ajusta a los principios de buena gestión, y equilibrio financiero.

En cualquier caso, de las definiciones expuestas, consideramos con Di RENCIO, que la efectividad del control proviene, de que junto con el elemento lógico o de juicio de todo control, debe añadirse una manifestación de voluntad productora de determinados efectos jurídicos, una medida de algún modo punitiva o cuanto menos, represiva o obstructi$v a$, como efecto lógico del control. Aquí, reside su eficacia e importancia, como acertadamente resaltó GARCÍA DE LA MORA ${ }^{7}$, al considerar la función de control en la administración pública, como un poder más

\footnotetext{
${ }^{6}$ José Pascual García, «Régimen Jurídico del Gasto Público». Ed. BOE. Madrid, 1999, pp. 604 y ss.

${ }^{7}$ Citado por M. A. Martínez Lago, «Manual ...», op. cit., p. 295.
} 
dentro del Estado de derecho. Por su parte, la INTOSAI ${ }^{8}$ considera que el fundamento del control, lo encontramos tanto en la obligación de rendir cuentas, por parte de las personas y entidades que manejan fondos públicos, que no son propios, como en la necesidad, de que dicha obligación se lleve a cabo en la forma correcta, inteligible y ordenada, es decir, con la máxima utilidad.

$3^{\circ}$. En un aspecto más actual, partiendo del Derecho Privado y de disciplinas como la Contabilidad u otras técnicas de control aplicadas, como la Auditoría, vemos que ya no solo se entiende el control interno, como una actuación o actividad de control, sino que responde más a un sistema, el sistema de control. Así el informe $\mathrm{COSO}^{9}$ lo ha definido, como: «Un proceso, efectuado por la dirección y el personal de la enti$d a d$, diseñado con el objeto de proporcionar un grado de seguridad razonable, para conseguir unos objetivos específicos» Definiéndolo por tanto, como realidad, que tiende a englobar todas las fases interrelacionadas, de un mismo proceso. Una definición más reciente del control interno, siguiendo esta orientación la encontramos también, en las normas de Auditoria del Sector Público, según Resolución de la IGAE, de 1 de Septiembre de 1998 (BOE. 30 de Septiembre), donde en su apartado, 5.2. Establece al definir el control interno, como: el «Plan de la organización, así como el conjunto de medidas, métodos y procedimientos, con el objetivo de:

- Salvaguardar y proteger activos y patrimonio. Evitar errores, perdidas, prevenir daños.

- Asegurarse de la fiabilidad e integridad de la información sobre la realidad del ente.

- Asegurarse del cumplimiento de las normas y regulaciones aplicables.

- Garantizar la gestión eficiente y eficaz de los recursos públicos, y

- Garantizar que se logren las metas y objetivos establecidos en los programas públicos.

\footnotetext{
8 INTOSAI, «Normas de Fiscalización y Auditoria», (1989).

9 CoOpers \& LyBrand, «Los nuevos conceptos del control interno», (COSO), Ed. Díaz de Santos. 1997.
} 


\section{EL CONTROL INTERNO HERRAMIENTA PARA EL LOGRO DE OBJETIVOS}

Los anteriores objetivos instrumentales, nos sintetizan por tanto, los fines básicos del control interno, como realidad necesaria para la gestión local, pero para su estudio, aquí se van a agrupar de forma diferente, conforme a la nueva Ley 47/03 de 26 de Noviembre, General Presupuestaria. Así, la «salvaguarda de los activos y la fiabilidad de las cuentas», como objetivos que debe verificar el control, los englobaríamos dentro de lo que denominamos, la obligación de rendir cuentas, como imposición democrática, en todo tipo de gestión colectiva. El objetivo de garantizar, tanto el «uso eficaz y eficiente de los recursos, como el logro de las metas y programas propuestos», están en la raíz económica del control, por la cual toda la gestión local, debe incardinarse, en un sector público más amplio y acoplarse con los demás miembros, tanto en beneficio de su buena gestión financiera, «Control Presupuestario», como dentro del concepto de Estabilidad y Equilibrio de todo el sistema, a través de la función de Control Financiero y de Auditoria. Por último, pero no con menor importancia, se debe estudiar el objetivo de legalidad y de cumplimiento de las normas, que tiene en la actualidad un mayor desarrollo, mediante el control previo de legalidad, a través de la función Interventora.

\section{III.1. Objetivo democrático de la rendición de cuentas en los Entes Locales}

El principal fundamento del control al que deben someterse, los entes locales en casi todos los países europeos, en primer lugar ante los parlamentos y gobiernos nacionales, viene dado, por que la gestión pública de dichos entes locales, a diferencia, de los particulares, las entidades privadas o de otros sujetos que desarrollan su actividad, bajo los poderes de un Estado concreto, se realiza siempre, con medios o recursos ajenos, y no, con las propias aportaciones, fondos o medios, de los gestores locales, motivo por el que deben rendir cuentas. Aportaciones que por tanto, no encontramos en el ámbito público, como es el valor entregado por acciones o títulos de capital, en una empresa o negocio particular, y con las que se responde del resultado de dichas gestiones. Incluso en una Asociación, ONG, Club Deportivo o Fundación benéfica, se respondería, siempre ante los socios, patronazgo u órganos encargados de la tutela de los mismos, por las decisiones tomadas para la consecución de un fin, por sus gestores o directivos. 
Además los entes locales y la administración pública en general, cuentan con unos poderes, instrumentos o medios, para el cumplimiento de sus fines, que se reconocen como, exorbitantes o fuera del denominado derecho común, que se aplica al resto de entes o sujetos que conforman el Estado. Privilegios públicos, que son concedidos por la Ley, para la realización de unos fines públicos concretos, según la institución a la que corresponda la competencia legal a ejercer o desarrollar, (ya sea realizar la captación de agua, en una cuenca hidrográfica, otorgar un mayor aprovechamiento urbanístico, o imponer una tasa por la explotación radiofónica). Circunstancia por la cual, todos los Parlamentos y en su caso, Gobiernos dentro de la Unión Europea, tienen una obligación de controlar la aplicación de dichas potestades, instrumentos y recursos ${ }^{10}$.

Esa idea, el control debe alcanzar no solo el uso que se hace con dichos recursos y poderes, sino también de los resultados logrados. Más si consideramos, que los patrimonios, derechos y demás activos públicos, tienen un carácter indefectible, es decir, deben permanecer siempre, aún introduciendo modificaciones y cambios sobre los mismos, por encima de las personas que transitoriamente los gestionan en un momento dado, y estar por ello, hábiles para el fin o servicio, al que colectivamente estén destinados (Interperiod Equity), motivo por el cual, deben estar más vigilados o sometidos a fórmulas y mecanismos de control. La idea de control, por tanto preside todo el sistema democrático, como descargo de dicho mandato y sus responsabilidades, y conlleva lo que debemos entender, por obligación de «rendición de cuentas y resultados», «Accountability», o «rendición de responsabilidades», de dichas entidades. La actuación pública por tanto, al ubicarse dentro del sistema democrático implica siempre, la justificación de la gestión realizada. La actividad de control se efectúa primero, mediante la celebración de elecciones periódicas, para la obtención de un mandato temporal, y posteriormente por la obligación del sistema democrático, de aprobación de las decisiones en órganos colegiados, (Asambleas, Plenos) mediante mayorías de votos. Pero dada la temporalidad de dichos mandatos, existen obligaciones complementarias, que obligan a rendir cuentas concretas, de las gestiones y del empleo de los patrimonios y recursos utilizados, y por la complejidad técnica que se precisa para su utilidad, las mismas deben efectuarse a través de órganos especializados y cualificados, que actúan por encomienda de los parlamentos y gobiernos que financian a dichas entidades. La función de control interno local por tanto, tendría como primer objetivo, la realización

\footnotetext{
10 S. FuENTES VEGA, apunta que aparte de la utilización de recursos, que no son propiedad de quien los utiliza, en la actualidad, se le une la importante cuestión, de que los mismos son escasos. «La Ejecución del Gasto Público: Procedimientos y control». I.E.F. Madrid, 1994.
} 
transparente y uniforme de estas obligaciones, en cuanto que seria el encargado de: registrar, confeccionar y hacer pública, la información y los resultados, que exige la correcta rendición de cuentas de los actos que realizan los gestores. Y ello, como única garantía, de la calidad, utilidad, fiabilidad y relevancia inherente a la misma ${ }^{11}$.

\section{III.2. Objetivos Económicos, Presupuestarios y de Estabilidad}

La actividad que realiza todo el sector público, ya sea local, estatal o autonómico, debe ser también considerada, como una parte dentro del todo que supone la actividad económica de los Estados Modernos. La Hacienda y la Economía Pública actual consideran que en el reparto de funciones, entre los gobiernos centrales y regionales, las entidades territoriales deben en términos óptimo Pareto-eficiente, dedicarse mayormente a la prestación de servicios y asignación de bienes, mientras que las otras funciones, con ciertas salvedades competen a las autoridades superiores, es decir, la regulación pública general, para ser eficiente, debe estar en manos superiores; lo mismo, que las políticas de estabilización de precios, monetaria o la redistribución de renta y riqueza, como actividades que a nivel inferior, presentan ineficiencias. En la actualidad también R. Jones y M. PEndelbury ${ }^{12}$ fundamentan una nueva visión, de la relación de control, basada en la búsqueda de incrementos de eficacia y calidad en la gestión de los servicios, que se prestan por las entidades locales, siendo por tanto ello, causa de la implementación, de métodos de control, tanto interno y como externo, por los gobiernos locales.

\section{III.2.A). Objetivos Macroeconómicos y de Estabilidad}

La moderna económica pública, considera que los gobiernos centrales deben de mantener una visión estratégica global, sobre la actuación de todos los agentes, que intervienen en la ejecución de las políticas económicas nacionales. Por estas razones, es esencial que el gobierno mantenga una influencia decisiva, sobre el crecimiento de los impuestos locales, como sobre el volumen del gasto local, y ello tanto, sí la orientación eco-

\footnotetext{
11 J. MAGNET, «Elements de comptabilité publique». L.G.D.J. Systemes, 2001.

12 R. Jones y M. Pendelbury, «Public Sector Accounting» Financial Time. Prentice Hall. London. 2000, p. 11.
} 
nómica, se fundamenta en planteamientos Keynesianos, como si se basan, en la tradición de economía Monetarista.

El planteamiento keynesiano, ha estudiado el control económico sobre las entidades territoriales, principalmente con el fin de controlar el agregado de la demanda y la evolución de todas las variables de la economía nacional, como la Renta, el Consumo la Inflación, el Empleo. Así, en épocas de recesión, las entidades locales suelen incrementar la actividad inversora, para amortiguar los efectos de crisis económica, intentando con ello, crear empleo, aumentando el gasto en infraestructuras o en servicios públicos. Este tipo de gastos, por el efecto multiplicador que suelen tener dentro del agregado nacional, en las siguientes fases del ciclo económico, principalmente en el entorno privado, revela la importancia que las entidades locales, tienen en el corto plazo, al poder inyectar incrementos, en el flujo circular de la renta. En España, todavía no es tan relevante dicha actividad, como en Europa, pero la tendencia es la del crecimiento continuo, hacia este postulado. En este sentido, el Gobierno al que le compete el control de las variables macroeconómicos, esta obligado a ejercer un control sobre dicho gasto local, que puede estimular la demanda agregada. Es más, la teoría económica moderna postula, que es preferible que el mismo, cuando sea preciso se realice en gastos de inversión, que en gastos corrientes, puesto que este último deben financiarse con ingresos corrientes o impuestos, suponiendo por tanto, una disminución de los recursos disponibles, en ese momento en manos del sector privado, a diferencia del gasto de inversión, que es posible financiarlo con préstamos o emisión de deuda, lo que siempre supone una adición de recursos, a la demanda agregada, pues se pagarán o devolverán en el futuro. Por dichos motivos, el control que deben ejercer los gobiernos centrales sobre el endeudamiento, no puede dejarse al arbitrio de múltiples decisiones locales, motivo por el cual se suelen incluir como prohibiciones en las leyes, como es el Art. 53 del TRLRHL.

Por su parte, los monetaristas, consideran el planteamiento anterior, muy alejado de la realidad y por ello, extremadamente vago, así hoy, después de más de 60 años, con la misma receta, los resultados son difíciles de apreciar. Por ello, el control de la actividad subcentral, estribaría principalmente, en el control de la oferta monetaria, que deben ejercer los Estados de acuerdo con el crecimiento y nivel de producción real, de una economía. Así, si el gasto local requiere financiación, por ejemplo, mediante la emisión de deuda local, que es un fácil sustituto de los activos e instrumentos monetarios estatales, como son el dinero del banco central o las obligaciones bonos o cédulas, puestas en circulación por el gobierno, vemos que una total libertad de las entidades locales 
para endeudarse, implicaría una reducción de las posibilidades de control del gobierno, sobre los tipos de interés y la oferta monetaria en general, implicando además la posibilidad de que dicha actuación, pueda incidir en la confianza, que internacionalmente, se otorgue a la política monetaria de un Estado. En conclusión, según los monetaristas los elevados tipos de interés de la deuda local, resta posibilidades de liquidez al entorno privado y por tanto, de capacidad de compra, por ejemplo, de la deuda estatal. Por estos motivos, existen fundadas razones, para el control del endeudamiento y por ende, del gasto público local, de manera que no tenga efectos perversos sobre la demanda agregada, puesto que crecimientos del gasto local, debería limitarse o estimularse, controlando la influencia, que pudiera tener sobre la inversión privada, o la inflación en general, dado que por ejemplo, el Art.149.1.13 de la Constitución Española, encomienda al Estado, la ordenación general de la Economía. Por ello, las leyes actuales como el Art. 107 del Texto Refundido de Régimen Local, mantienen un control sobre ciertos actos de autorización de precios y tasas locales, con amplia incidencia, en los procesos productivos en que interviene un ente local, como agua, transporte, vivienda o energía.

\section{Control de la inflación}

Tanto por las consecuencias que provoca el endeudamiento local, como por las características, de la imposición de las entidades locales, según lo apuntado anteriormente, ambas pueden ser también causa o motivo, de variaciones en la tasa de inflación. Así, un incremento de la presión impositiva, supone una minoración de las rentas disponibles y estimula por ejemplo, el crecimiento de protestas y reclamaciones salariales y por tanto, el crecimiento de la inflación, vía costes de salarios. En el mismo sentido, dado que también muchas de las subvenciones que financian a los entes locales por parte de los Estados, incluyen costes laborales, los incrementos que se calculen en las mismas, suponen que para obtener una misma cantidad de producción o servicio, o bien, se disminuye el precio de la hora de salario efectivo, o bien, que deban compensarse, con una mayor aportación de fondos del gobierno central, siendo una limitación a su crecimiento. Motivo por el cual las propias leyes, incluyen limitaciones y actuaciones para el control de estos gastos, Art. 90 y ss. de la Ley de Bases del Régimen Local. 


\section{Asignación y reparto de recursos}

En los últimos tiempos, como comenta BAILEY, las aportaciones doctrinales del análisis económico actual, se centran más, en la forma en la que debe efectuarse la distribución de recursos, entre el sector público y el privado, que en como ha de repartirse o asignarse entre el sector Estatal y el Subcentral. En principio, siguiendo a este autor, vemos que en la mayoría de los casos, dicho reparto, es una circunstancia determinada por las leyes. En este sentido la asignación de los recursos, no deja por ello, de estar empañada de una visión política, donde se establecen las prioridades en la asignación ${ }^{13}$ y siendo, tanto los gobiernos locales, como los nacionales elegidos democráticamente, ambos pueden efectuar estos servicios.

El argumento por el cual, el Gobierno Central debe mantener un control sobre el local, viene establecido en la propia Carta Europea de la Autonomía local, cuyo art. 9.1. Establece que: «las entidades locales en el marco de la política económica nacional, tienen derecho a tener recursos propios suficientes, de lo que podrán disponer libremente en el ejercicio de sus competencias». En esta línea, consideramos con D. KING ${ }^{14}$ y también, con S. BAILEY ${ }^{15}$, que los gobiernos centrales deben mantener la última responsabilidad y el control en la determinación de los recursos y nivel de servicios, si se dan algunas, de las siguientes condiciones:

1. Si en la prestación del servicio de forma centralizada se obtienen ganancias de eficiencia, por lo que suponen las «economías a escala».

2. Si una parte importante el gasto local, esta comprometido mayormente, por obligaciones legales impuestas por el gobierno central, y que se financian por él, (Hoy casi el 50\% del gasto local), como son la educación o la sanidad, con importantes efectos sobre los miembros de la comunidad nacional, residan o no, dentro de un término municipal.

3. Por otra parte, si para este tipo de servicios, el gobierno central suele hacer aportaciones financieras, relacionadas con el esfuerzo realizado por la entidad local, esto puede hacer que se incremente deliberadamente el gasto local y con ello, incluso el gobierno central,

\footnotetext{
13 S. BAILEY, «Local Government Economics», Macmillan. London, 1999.

14 David King, «La Economía de los Gobiernos multinivel», Instituto de Estudios Fiscales. 1988, pp. 65 y ss.

15 S. BAILEY, «Local Government Economics» Macmillan. London, 1999.
} 
podría verse en la necesidad de incrementar, su propio nivel de imposición.

4. En España, como en Europa, gran parte de los impuestos los pagan la actividad económica que radicada en el término. La teoría de la incidencia impositiva, sugiere que los gravámenes sobre las empresas, se trasladan a los consumidores vía precios, trasladando sobre consumidores que no residen, ni se benefician de los servicios de la entidad.

5. También, sí una gran parte de los recibos de servicios locales son trasladado hacia otros terceros, por ejemplo, mediante las ayudas o subvenciones al transporte, o incluso repercutiéndolos hacia delante, al Estado o a la Administración superior, como es el caso de los recibos de inmuebles, con reducciones o bonificaciones, por ejemplo de viviendas protegidas.

6. También, si una parte importante del gasto, va a ser pagada por generaciones futuras de contribuyentes, mediante deuda pública, lo que hace que requieran cierta protección, puesto que se verán obligados a pagar las deudas del pasado ${ }^{16}$.

Vemos que también se justifica así, una cierta intervención de control de dichos parámetros, bien por mandatos legislativos, sobre los niveles impositivos y sobre el volumen del gasto público que realizan las entidades locales, y que los órganos de control interno suelen vigilar, evaluar o certificar de forma independiente, para corregir estos defectos en la provisión de los servicios. El control interno local sobre los ingresos se regula, por ejemplo, en las ordenanzas fiscales, al requerir memorias y justificaciones técnicas para su aplicación, o también mediante la justificación contable de sus costes, en la aplicación de exenciones y bonificaciones fiscales en los servicios locales, o en el cálculo transparente de la carga financiera de la entidad.

\section{III.2.B) El control Microeconómico de la gestión presupuestaria}

La idea principal de este apartado, es que las entidades locales deben producir los servicios públicos de su competencia, de forma eficiente, es decir, sin pérdidas y en un determinado nivel de calidad. La asignación de

\footnotetext{
16 Un estudio más amplio de los efectos de la deuda local, en Monasterio y Suárez Pandiello. «Manual de Hacienda Autonómica y Local». Ariel Economía. Barna, 1998, pp. 47.
} 
recursos y prestación de servicios locales, no ha sido estudiada todavía, desde la perspectiva de considerar las decisiones locales, dentro del proceso de producción de servicios y obtención de resultados, con problemas propios como el exceso de producción, la adecuación a las necesidades reales del entorno, capacidad ociosa, supuestos de pérdidas continuas, etc. Esto cada vez es más frecuente, en el mundo local, puesto que muchas subvenciones y transferencias de ingresos, se condicionan, al logro de unos resultados, o para que los esfuerzos, sean realizados en un determinado sentido. El control presupuestario y de gestión interna tiene aquí su más amplio fundamento, entre otros, por los siguientes motivos.

\section{Los grupos de interés y las decisiones del gasto}

Las organizaciones, tanto públicas como privadas, pueden ser tomadas como coaliciones de distribución, que buscan promover el máximo beneficio de sus miembros, accionistas o clientes, en la conocida Teoría de las coaliciones, formulada por MANCUR OLSON ${ }^{17}$, para explicar las diferencias de crecimiento de los países. Dicha teoría es aplicable y puede ser trasladada a las entidades locales, puesto que estas actúan como coaliciones de usuarios de servicios en el reparto del gasto público, buscando de una parte, incrementar las transferencias y beneficios a sus vecinos, por ejemplo, ante el Estado, que financia hoy la parte más importante de ese Gasto y de otra, como receptora de presiones de los grupos locales, para la asignación y distribución del mismo.

Los entes locales de una parte, se comportan como coaliciones de este tipo, cuando realizan servicios concretos, que no se pagan con impuestos o tasas propias, sino con transferencias que puedan recibir del Estado, en este sentido, tienden a destacar, la justicia y los derechos que el sistema ha establecido, para con ello, incrementar los subsidios y transferencias a su favor, restando las escasez o restricción que suponga, la ineficacia en su actuación. Estas, actuarán interesadamente mientras, las ganancias que se reciben, por medio de subvenciones o por cualquier otra redistribución pecuniaria del Estado, sea mayor, que la perdida, en la que puedan incurrir por dicha circunstancia, al carecer de algún tipo de sanción.

Por otra parte, mientras que la imposición local no esta relacionada directamente con la cantidad de servicio, que se consume individualmen-

\footnotetext{
17 N. Bosch \& J. SuÁREZ, «Hacienda Local y elección publica: El caso de los municipios españoles» Ed. Fundación BBV. Bilbao, 1994, pp. 57 y ss.
} 
te, siempre existirán incentivos para que grupos de interés sectoriales, presionen a las entidades locales para que les financien todo o parte de una actividad o servicio, aumentando el nivel de producción del mismo o bien, cambiando su distribución, en beneficio de sus allegados-usuarios. En ese sentido, la teoría económica consideraba que los grupos de interés o presión, dado que podían tener múltiples y variadas finalidades en su actuación, se compensarían unos con otros, nivelándose entre ellos y tendiendo a hacer irrelevante, el hipotético poder que pudieran gozar ${ }^{18}$.

La teoría de Mancur Olson demostró que esto no es así, que no todos los grupos tienen las mismas posibilidades de influencia, puesto que no todos, tienen las mismas probabilidades de organizarse en defensa de intereses propios, dado que la naturaleza y efectos de la actuación de los grupos de interés, tienen las características típicas de un bien público, en relación al conjunto de individuos que comparten ese interés. En este sentido, si dentro del grupo se consigue promover un aumento del interés o bienestar del mismo, se beneficiarán todos los componentes, aunque no todos estén integrados en su acción, de esta forma, como pertenecer al grupo es costoso en tiempo y dinero, pero se pueden disfrutar de las ganancias, sin ser actor de las mismas, los individuos actuarán, por tanto, como «usuarios gratuitos ${ }^{19}$, haciendo depender de dicha nota, el que unos grupos subsistan y otros no. Por este motivo un rígido control presupuestario, la fiscalización previa, junto con una programación basada en el análisis cuantitativo y no subjetivo o político, es una herramienta imprescindible hoy, para mejorar y lograr los objetivos del presupuesto anual, coadyuvando a superar este tipo de debilidades.

\section{El monopolio en la prestación de servicios locales}

La falta de una valoración económica de los resultados, en la oferta de muchos de los servicios locales, así como el particular marco legal de competencias locales, que no establece ninguna limitación a la gestión de cualquier actividad realizada por los entes locales ${ }^{20}$, producen en el sector

\footnotetext{
${ }^{18}$ Bosch \& SuÁReZ, «Hacienda Local y elección pública: El caso de los municipios españoles». Ed. FBBV .Bilbao 1994.

${ }^{19}$ Es decir, no revelar sus preferencias, ní contribuir, ni militar activamente, pero sí beneficiarse de la actividad de los que lo hagan. Monasterio y Suárez Pandiello. «Manual de Hacienda.....». op. cita, p. 27.

${ }^{20}$ Sobre la posible competencia universal de los entes locales, vide, J.M: DíAz MENA, «La influencia del Derecho Europeo en la actuación económica de las entidades locales», Cunal, Revista de Estudios Locales; Julio 1998, p. 75.
} 
local, una gran laxitud y falta de disciplina presupuestaria. Esta situación, provoca incrementos de ineficacia, en la asignación de los recursos disponibles, dentro de las posibilidades internas de una economía. Algunos de los servicios típicamente locales, no todos, se producen en una situación de monopolio, bien establecido por mandato legal, bien por causas naturales, monopolio natural de costes fijos decrecientes o circunstancias similares. En cualquier caso, esta comprobado que las situaciones de monopolio, provocan ineficacia, puesto que como ya sabemos, el monopolista actúa maximizando las ganancias, es decir produciendo por tanto, mayor cantidad de la óptima del mercado en concurrencia (Que sería aquella que iguala, Ingreso marginal $=$ coste marginal) y con ello, ineficacia, por la perdida que supone el no aprovechamiento social, del denominado «excedente del consumidor».

En una empresa privada, los problemas de organización, se resuelven según la condición de maximizar sus ingresos, para lo cual, intentan producir al mínimo coste interno. En el monopolio la producción, al no existir competencia, se realiza a mayores costes que los mínimos, porque como sabemos puede vender, a más del ingreso marginal, existiendo por tanto lo que llamaríamos holgura, o margen, para no aprovechar más eficientemente los recursos, dado que puede valerse de dicha posición de monopolio. Así, se puede pagar más, que lo estrictamente necesario por una compra, o emplear más recursos de los necesarios, en la producción de un servicio concreto. En la provisión mediante monopolio, los costes se elevan por encima del mínimo, en un defecto, del cálculo de los precios, fundamentalmente en el empleo del factor trabajo. En conclusión, esta claro que existen diferencias de producción, en las entidades del sector público, porque también existen deferencias en el sector privado, por ello la reorganización interna, como medida de incremento y mejora, la cultura del gasto publico, inversa a la actual, donde se tiende a incluir y agotar las partidas en los presupuestos públicos, para que no se disminuyan en los años y presupuestos sucesivos, o como sinónimo de poder o buena gestión, pero separadas de los resultados, implican razones para que se tomen medidas y se apliquen sistemas de control internos y de gestión, que limiten estas disfunciones, efectuando una gestión presupuestaria basada en objetivos y resultados, que reduzcan en lo posibles la ineficacia, que la prestación de los servicios en monopolio, siempre produce.

\section{Problemas burocráticos decisión presupuestaria}

La moderna teoría de la hacienda pública, ha considerado el modelo anglosajón de la Agencia, como un intento, para explicar y mejorar las 
estructuras públicas. Esta teoría explica, inicialmente las relaciones en las grandes compañías multinacionales y sociedades, donde la titularidad de las acciones corresponden a la propiedad del capital, siendo este, el que designa al agente o gestor del negocio, que es la persona o consejo de administración, que ejecuta la política a seguir, de acuerdo con un mandato o convenio previamente definido, (Remuneración, objetivos, plazos, etc.).Esta sería, la interpretación que en el campo público, principalmente anglosajón, se ha dado, a la teoría de la Agencia, donde el electorado elige el principal-político, por un espacio de tiempo y este, debe encomendar al agente, normalmente al oficial del departamento, la gestión de los asuntos públicos. El modelo agente-principal, es estudiado por NISKANEN, y basa en el, su modelo de la Burocracia, para explicar en parte, la gestión del sector público. Aclarando algunas ideas, diremos que en este, la maximización del beneficio del agente o burócrata, no solo se consigue, con una mejora en la retribución salarial, sino, que es una función de utilidad, que contiene muchas variables, salarios, reputación, poder, ganancias en especie, etc., pero todas ellas tienen que ver con el tamaño del presupuesto a ejecutar, por mandato del principal. De tal manera que maximizando el presupuesto, maximiza su utilidad ${ }^{21}$.

Dado que modelo burocrático, otorga un papel excesivo al gestor burocrático, ha sido sometido por A. PEACOCK y otros ${ }^{22}$, a una redefinición, sin embargo, en la actualidad dicho modelo, sigue sirviendo como importante justificación teórica, de los vicios que presenta el sistema de producción de los servicios públicos, por lo menos en la interpretación del gestorburocrático. En cualquier caso, el Agente siempre, tiene una condición más favorable, porque es además quien suministra la información, de cos-

21 Debemos puntualizar en este aspecto, que la traslación a la dinámica local Española, de la teoría de la Agencia, supone asumir alguna restricción interpretativa, cuanto menos a nivel local, puesto que aquí, no son los funcionarios locales los encargados de la gestión y realización del gasto presupuestario, es decir, no deciden, contratan, o ejecutan el mismo, sino que por Ley, estas competencias están atribuidas al Alcalde-gestor, que también acumula, los roles de representante del gobierno, del propio partido, presidente de la Asamblea local, cuentadante de los fondos municipales, jefe de personal, contratación local, y otras áreas de gestión, máximo interprete jurídico en los recursos previos judiciales, y poder ejecutivo de las máximas potestades públicas, como expropiaciones, embargos, organización de los servicios, sanciones, disciplina, etc. Con un diseño de competencias y acumulación de actuaciones, creemos que muy contrario al principio de división de poderes, diseñado por Montesquieu, y ello, a parte de la complejidad técnica, que actualmente dicha gestión requiere. En este sentido y a efectos ilustrativos de la teoría agente-principal, un ejemplo práctico, lo podríamos encontrar, en la organización de las Cajas de Ahorros Españolas, donde los representantes políticos, actúan exclusivamente en los órganos rectores-deliberantes, sin intervención en la gestión de la entidad, sometida, por ello, a unos fuertes controles por el Banco de España, $\mathrm{M}^{\mathrm{o}}$ de Hacienda, etc.

22 En, Albi, González-PÁramo y Casanovas, "Gestión Pública». Ed. Ariel Economía. Barna 1997 , pp. 58 y ss. 
tes y resultados. Esta es, en nuestra opinión, otro gran fundamento para separar el servicio de información contable municipal, del gestor AlcaldeAgente, dado que se deben dar datos contables independientes, transparentes y no sesgados, que manifiesten la utilización de los recursos públicos. (Similar fundamento justifica la actividad desarrollada, por la Audit Commissión en Inglaterra ${ }^{23}$.

En este sentido, vemos que existen amplios argumentos para controlar o disminuir los efectos nocivos, que una excesiva producción u oferta de servicios públicos locales pudiera presentar. Así de una parte la ineficiencia de costes, se puede reducir, si el gobierno central determinan los niveles de producción de un servicio, o indirectamente, aprobando incluso los presupuestos $^{24}$, por su parte la «ineficiencia X o de diseño» requiere estudios individuales en cada caso, de los servicios, organismos y empresas, para conocer cuales son las prácticas, en orden a eliminar, las perdidas provocadas por la organización y producción de los mismos. De cualquier manera, esto no impide la necesidad de otro tipo de controles para reducir el poder de monopolio del gestor-alcalde, como es reforzar los sistemas de información, entre otros, con una contabilidad independiente del gestor, enfocar ciertos servicios a la contratación exterior ${ }^{25}$, más que a la producción interna, mediante procesos contractuales, que deben quedar siempre, adecuadamente vigilados o incluso a la provisión coordinada en un nivel superior, ya sea nacional o autonómico, buscando economías a escala, sin necesidad de salir del sector público.

\section{III.3. Objetivos Constitucionales y Legales}

Debemos también en este trabajo, citar otro tipo de los objetivos, que justifican la creación y empleo de instrumentos de control, sobre la gestión de los servicios que realizan las entidades locales y territoriales y que se basan en este último apartado, en el principio de legalidad, y en razo-

\footnotetext{
${ }^{23}$ Audit Commission. «The impact of local Authoritie's efficiency of the Block Grant Distributión System» HSMO. 1999.

${ }^{24}$ Este sería por un lado, el sistema de control de tasas o precios autorizados, ya comentado anteriormente y por otro, el de tutela, que se mantiene vivo en otros países, como Portugal, Alemania y Holanda.

${ }^{25}$ Un interesante trabajo en TORRES y PINA, European Accounting Review. Nov. 2001. «Public-Private partnership and private finance iniciatives in EU and Spanish local Governments». Si bien, del propio estudio vemos, que en los doce países europeos estudiados, funciones, como los servicios de nóminas y financieros locales, no son de hecho, susceptibles de fórmulas de descentralización o participación privada, por su naturaleza como garantía de la entidad.
} 
nes de seguridad jurídica colectiva, que como administraciones públicas, las entidades locales deben cumplir, dentro de la organización constitucional del Estado, si bien aquí los enumeramos, sin revisarlos con extensión, así con J.L. GARCÍA GARCÍA, podemos resumir más sistemáticamente los mandatos Constitucionales, referentes al apartado del control financiero y presupuestario, de la siguiente manera ${ }^{26}$ :

- Principio de Legalidad General, Tributaria y Presupuestaria. Arts.: 9.3; 103,133; 134 .

- Principio de Igualdad, progresividad y carácter no confiscatorio de los Tributos, Art. 31.1.

- Principio de Asignación equitativa de los recursos públicos.- Art. 31.2 .

- Principio de Eficiencia y Economía en la programación y ejecución del Gasto público.31.2.

— Principio de Eficacia de la Administración. Art. 103.1.

- Principio de Planificación contable y Rendición de cuentas, Art. 134; 136; y 153.d.

De igual manera, la doctrina administrativa, ha citado otros fundamentos de naturaleza jurídica para el control de las entidades locales, así MuÑOZ MACHADO, considera que la descentralización, conlleva siempre el control del poder central, sobre las competencias cedidas o delegadas, con quien resumiremos, los criterios más relevantes que justifican el mismo ${ }^{27}$.

- La autonomía existe dentro del ámbito de los respectivos intereses $\mathrm{y}$ por tanto, debe asegurarse que el ejercicio del autogobierno, se mantiene dentro de los límites legales.

- La Ley que delimita el contenido de la autonomía, puede incluir como uno de sus elementos, el sometimiento al control de los entes locales.

- En el sistema de competencias locales, los entes locales actúan ejecutando competencias ajenas y los parlamentos tienen derecho, a saber como se ejecutan y que problemas provocan.

\footnotetext{
26 J.L. GARCíA GARCÍA, «El control interno» en la obra colectiva «Control del sector público». Ed. I.E.F. Madrid 1981.

27 E. Giménez y Corrons, «Los Controles administrativos....», op. cit, pp. 39 y ss.
} 
FUNDAMENTOS, CONTENIDO Y DERECHO COMPARADO DE LA FUNCIÓN DE CONTROL INTERNO...

- Además debe asegurarse que la tarea aplicativa de las normas, se realiza sin lesionar la regla de igualdad de derechos de los ciudadanos, en todo el Estado.

- La Jurisdicción contencioso administrativa, es insuficiente para ejercer el control sobre los entes locales, de forma que su función no es vigilar de forma permanente, la actividad de la entidad local, sino singularmente actos concretos, que son sometidos a su jurisdicción.

- Parece lógico que deba hacerse prevalecer, la autotutela de los actos que responden a intereses más generales, como los políticos del Parlamento o el Gobierno Central, de manera que no tiene sentido, una supremacía o prevalecida, de los actos de la administración local.

- Por último como hemos visto, si expresamente la Constitución establece, en el art. 153, el control directo del Gobierno sobre las Comunidades Autónomas, no parece lógico que los entes locales, tengan por tanto, una autonomía, de mayor y más cualificada condición.

El control de legalidad sobre la gestión financiera, por tanto, es inherente al estado de derecho, y es una de los objetivos básicos, a desarrollar por los órganos de control interno local. Sirviendo también así, como fundamento para el establecimiento de mecanismos y funciones de control interno, en las entidades locales.

\section{NATURALEZA DEL CONTROL INTERNO EN LAS ENTIDADES LOCALES}

Llegados este punto, y una vez analizados los fundamentos y objetivos básicos que debe perseguir el control interno, y de las definiciones ya vistas podemos apuntar, que el control interno local posee cuanto menos, las siguientes notas:

A) Es un control que efectúa dentro de la organización, como actividad integrada y regular de supervisión en el seno de la misma, no es por tanto, un acto esporádico, sino una función.

B) Dicha actividad se efectúa por personas, que realizan una tarea diferenciada de control, con unos objetivos prefijados y con unas cualidades y atributos singulares. 
C) Dicha actividad o función, proporciona una seguridad razonable, pero nunca total, del logro de los fines y objetivos propuestos.

D) Para su efectividad, requiere un cierto poder de corrección, o cuanto menos de suspensión o paralización sobre los actos que se realizan por la administración y la gestión.

E) Por el sentido codificado y reglamentado de la administración pública continental tiene una Mayor relevancia el control interno en el cumplimiento de las normas.

Junto con estas características básicas, el análisis mas detenido de cual es la naturaleza del este control, o mejor de la actividad o función continuada de control interno, nos presenta distintas ideas o nociones, así algunos autores, como GARCÍA DE LA MORA, consideran el control, como un conjunto de medidas y dispositivos adoptados por el ordenamiento para asegurar un grado amplio de legitimidad, regularidad e incluso conveniencia, en la actividad financiera de los entes públicos, es por tanto, una idea mas amplia que la sola función interventora.

BOHOYo CASTAÑAR ${ }^{28}$ por su parte manifiesta, que la definición del control en la administración publica, no esta clara, pero si las notas básicas que conforman al mismo, por cuanto incluyen. A) La función de revisión crítica o juicio. B) La existencia de varios sujetos, controladores y controlados. C) La potestad o poder para revisar y enjuiciar y D) La necesidad de que exista un termino o referencia previa, con el que comparar y valorar el juicio.

Para este autor incluso, el acto de control es una valoración o juicio previo, sobre la legalidad de un acto, que tendría incluso, la naturaleza de acto administrativo, si bien, con unas características determinadas que lo conforman, como son:

- Acto de control, en contraposición a actos de la administración activa o consultiva.

- Acto dependiente, pues se ejercita en relación a procedimientos determinados, actos conformes, paralizantes o suspensivos o que inician una revisión de actos determinados.

- Acto no impugnable en la vía contencioso-administrativa.

${ }^{28} \mathrm{~F}^{\mathrm{o}}$. BOHOYo CASTAÑAR, El principio de legalidad financiera como presupuesto de validez del acto Ad ${ }^{\circ}$ - I.E.F. 1986. 
FUNDAMENTOS, CONTENIDO Y DERECHO COMPARADO DE LA FUNCIÓN DE CONTROL INTERNO...

- Acto reglado.

- Por tanto, para este autor el reparo, no es equiparable a un mero informe.

Otros autores, como ARNAU BERNIA, ven más la acción de reparar, como un instrumento que poseen los órganos de control interno, pero con una finalidad propia y determinada por la Ley, compartiendo la naturaleza y características de un informe escrito, preceptivo y previo en los expedientes administrativos, pero con los efectos propios y concluyentes determinados en la Ley de Haciendas Locales ${ }^{29}$. La actual Ley General Presupuestaria tampoco define la sustancia del control interno, si bien, si determina los objetivos y finalidades que persigue, englobando en él, todas las actividades y funciones de control del área Estatal, como la función Interventora, el control financiero permanente y la auditoria pública. En cualquier caso, por nuestra parte consideramos y así lo manifestamos en otros trabajos, que la eficacia del control interno local, estriba en las herramientas e instrumentos con que cuente el Interventor para la corrección de la actuación del gestor público, cuanto mayores y más amplios sean esos poderes, mayor será la posibilidad de corregir y por tanto, menores los fallos e incumplimientos.

Junto de estas primeras ideas, voy a considerar también, la novedad que en el análisis del contenido del control interno, tanto público, como privado, ha supuesto el planteamiento del Informe $\operatorname{COSO}^{30}$, en cuanto pueda considerarse una definición, más completa y universal de este, al definirlo como:

«Proceso efectuado por el consejo de administración, la dirección y el resto del personal de una entidad, diseñado con objeto de proporcionar un grado de seguridad razonable, en la consecución de unos objetivos, como son la eficacia y eficiencia en las operaciones y gestiones realizadas, la fiabilidad máxima en la información financiera, y el cumplimiento de las leyes y normas, que sean aplicables».

Dice el informe COSO que el control interno, es por tanto, un proceso o una serie reglas escritas o incluso costumbres de la manera de hacer, dentro en la organización, y que su eficacia es el estado o situación del cumplimiento de ese proceso, en un momento dado. Esta aseveración, nos plantean algunas cuestiones o interrogantes, que voy a comentar seguidamente:

29 V.J. Arnau Bernia, «Manual de Presupuestos de las Entidades locales». M. Pons. 1991.

${ }^{30}$ Los nuevos conceptos del control Interno. (Informe Coso) Ed. Díaz de Santos, 1997, pp. 5 y ss. 
A) De una parte, consideramos que la definición del mismo, como procedimiento o proceso, puede entenderse como una limitación, en cuanto que se interprete, que con el establecimiento exclusivo, de una reglamentación procesal escrita, o incluso, que con unos hábitos o costumbres internas sobre la gestión de la entidad, se acaba la actividad de control. En este sentido, por nuestra parte vemos, que no solo es necesaria esta base normativa que determina las reglas y tareas concretas del proceso, (Rules), sino que además de dicha normativa, en la naturaleza del control interno, se debe incardinar de manera incuestionable, una actividad repetitiva y permanente de vigilancia y más, en el ámbito público, donde dicha actividad debe realizarse mediante, la función de control a ejercer por unas personas determinadas y con unos requisitos diferenciados, (cualificación, independencia de criterio, medios y posibilidades, etc.) y por ello, con una naturaleza especial dentro de las organizaciones, dado que tienen un cometido especial. (Controllers, Interventores, Auditores, etc.). Aspecto que no esta suficientemente resaltado, en el informe $\mathrm{Coso}^{31}$, aunque se cite entre sus componentes, la supervisión, como elemento primordial, así:

1. El entorno de control, marca la pauta del funcionamiento de una organización e influye en la concienciación de sus empleados respecto del control. Incluyen la integridad, la ética, el estilo de gestión y la manera en que la dirección ejerce y asigna las responsabilidades. De aquí, la importancia de las conductas (Behavours).

2. La Evaluación de los riesgos, como actividad que consiste, en la identificación y análisis de los riesgos e impedimentos, para la consecución de los objetivos.

3. Actividades de control, como actuaciones y procedimientos que ayudan a asegurar que se llevan a cabo las instrucciones de la dirección y del control. La gama de actividades como luego veremos, es muy variada, autorizaciones, delegaciones, verificaciones «in situ», conciliaciones, custodias, arqueos, recuentos, etc.

4. Información y comunicación, se debe identificar, recopilar y comunicar información pertinente, en forma y plazo, que permitan cumplir a cada punto de la organización con sus responsabilidades, el diseño de los sistemas informativos deben ser la base, para realizar informes y controlar la actividad en tiempo, de tal forma, que fluya convenientemente, y con las garantías adecuadas.

31 Los nuevos conceptos del control Interno. (Informe Coso), op. cit. 
5. Supervisión o vigilancia, quizás en el ámbito publico, presente la mayor justificación de la función de control, puesto que el control debe implicar normas y procedimientos que deben diseñarse con una finalidad y objetivo interno, pero que deben vigilarse permanentemente por órganos especializados para verificar que se mantiene en adecuado funcionamiento a lo largo del tiempo y con ello, comprobar y prevenir el resultado de todo sistema.

B) Como desarrollo de lo apuntado, la función de control implica o debería implicar, para la persona encargada de dicha actividad, el Controlador o Interventor, cuanto menos, decidir y actuar sobre las siguientes tareas: Planificar y coordinar, las diferentes partes de la ejecución del plan de control, con la realidad de los recursos y componentes de la gestión. Organizar, las estructuras básicas del control, que quizás es la más limitada de las funciones a realizar en el campo público, al requerir e implicar, exigencias y decisiones, en materia de personal, instalaciones, procedimientos e incluso, en el diseño de la actividad de órganos colegiados, como consejos, comisiones, etc. Dirigir, las personas y el equipo, para que funcionen coordinadamente, al llevar a cabo el plan y la actividad de control y por último, Medir, creando los sistemas de información contable, que sean adecuados a los objetivos y fines reales, pero también, deben efectuar normalmente, una valoración e interpretación de los mismos y en su caso, la posibilidad de paralizar y corregir la actuación defectuosa. En el campo de las sociedades y compañías privadas, el desarrollo de dicha actividad se efectúa mediante el contrato de agencia con el personal profesionalmente adecuado, distinto al propietario de la entidad. En las organizaciones gubernamentales, por la naturaleza ya estudiada de las mismas, dicha actuación debe efectuarse por personal, con un estatuto especial, con la cualificación, responsabilidad finalidad y medios, que se adecuen al entorno que implica, la actuación pública.

C) Por otra parte y en concreto, en el ámbito público local, vemos la necesidad de efectuar la definición del control interno local, como actividad o función con una naturaleza dual o bifronte, puesto que la misma, entendemos que satisface necesidades internas y propias de la entidad, como son las apuntadas por el informe COSO, pero también, resuelve necesidades de la organización de los servicios públicos compartidos, con el Estado o las CCAA correspondientes, circunstancia esta, que ha sido remarcada incluso, por el Tribunal 
Constitucional, en numerosas sentencias ${ }^{32}$. Esta afirmación se justifica, porque el estado de derecho, es una necesidad Constitucional y su respeto y control, es más una función estatal, que local. Para M. BOUVIER ${ }^{33}$, la necesidad del cumplimiento de dicha finalidad, no puede ser omitida por parte del Estado, ni con relación a las Regiones, ni a las entidades locales, ni puede dejarse a la sola voluntad, del ente territorial. Es decir, ante las entidades otorgantes de la financiación, el órgano de control interno local, actúa con una encomienda de función, que choca, en muchos casos con los intereses de la entidad receptora de las subvenciones, que por decirlo claramente, siempre tendrá un mayor incentivo para incrementar dicha financiación externa, y por ello, tenderá a sesgar en interés propio, tanto la independencia, como los medios de comprobación del personal de control. Dado que cuenta además, con un amplio campo para influir en la orientación que se requiera (retribuciones, sanciones, promoción y cualificación del personal, etc.).

D) En el sector público español, hasta hace menos de dos décadas, la función de control ha hecho especial hincapié, en el aspecto legal de cumplimiento de las disposiciones, como la función principal del control interno, obviando en mayor o en menor grado, las otras finalidades del control y ello como vemos, por planteamientos legales y conceptuales muy limitativos. Es por ello, por lo que la definición del informe Coso anterior, nos parece poco completa, pues con FUENTES VEGA ${ }^{34}$ debemos anotar, que al ciudadano no le es indiferente el comportamiento de la administración pública, ni siquiera cuando actúa dentro del núcleo interno de la organización y esta es una diferencia sustancial, entre los tipos de control y que quiero también resaltar, por la incidencia que la misma presenta en el ámbito local, por cuanto, en el ámbito privado, la organización del control interno, es regulado por la misma organización, circunstancia que no es equiparable a los entes locales, que aunque cuentan con poder de autoorganización, al igual que la Administración del Estado, la estructura administrativa a controlar, les viene dada, o mejor dicho, impuesta por las leyes, incluso por la Constitución, debiendo adaptarse a ella, siendo esta nota, en algunos casos, un

\footnotetext{
32 Sentencias T. Constitucional de 2 de Febrero y 29 Abril 1981 y 117/84 de 5 de Diciembre. Otros comentarios en, $\mathrm{F}^{\circ}$. SosA WAGNER, «La Lealtad gozne del Estado». Rev. Estudios. A Local, n. 288. Enero-Abril 2002. Ed. INAP.

33 Michel Bouvier, «Les Finances Locales» L.G.D.J. Paris. 1999. También, JM. LarRainZAR GoNZÁLEZ, op. cit.

34 S. Fuentes Vega, «El RD.2188/95, de Control Interno a ejercer por la IGAE». Revista Presupuesto y Gasto Público, n. ${ }^{\circ}$ 18/1996.
} 
límite al control efectivo, más que una ayuda o colaboración al mismo. Por tanto, el problema organizativo de la gestión, esta estrechamente ligado al control interno, y nos introduce en las necesidades o medios que el mismo, como sistema requiere, para lo cual dentro de las organizaciones a controlar, es necesario para un efectivo control:

- Un plan de organización u organigrama o estructura similar, que proporcione una segregación de funciones y responsabilidades adecuada.

- Un sistema de autorizaciones y procedimientos de registro que proporcione la máxima seguridad y evidencia, a las operaciones realizadas y a los derechos y obligaciones contraídos.

- Un personal adecuado, y con el conocimiento adecuado, de las funciones que desempeña, es decir con la formación, capacidad, número y responsabilidad adecuada, a las tareas o trabajos encomendados.

- La realización de prácticas contables y de gestión en hábitos sólidos y por escrito.

- Un sistema de seguimiento y control que proporcione información útil y unos parámetros objetivos de evaluación, que sirvan a la toma de decisiones.

E) Como veremos seguidamente en este trabajo, en la mayoría de los países existe una relación intensa de colaboración, entre el Control Interno local y las realizadas por los Órganos de control externo, formando lo que podríamos denominar un sistema de control. Es más, entre las herramientas habituales que emplea el control externo, para la realización de sus trabajos, se encuentran las pruebas sustantivas y de cumplimiento que se realicen a la entidad, así como en los estados contables que confecciona el mismo, como en la información a suministrarse mutuamente, para la mejor gestión de los fondos y las responsabilidades públicas. Es por ello, que al examinar las relaciones entre ambos tipos de control, interno y externo, en las entidades públicas, llama la atención, la separación en muchos casos intencionadamente artificial y distante, no sabemos porque motivo, que existe entre ambos, principalmente con el Tribunal de Cuentas del Reino. Distancia que en la ejecución de funciones, se opone y limita la efectividad el control interno local, sobre todo si lo comparamos, con la cada vez mayor necesidad de información y control mutuo que se viene realizando e implantando en la actividad privada, (banca, bolsa, seguros) por su administración supervisora, o en las entidades locales europeas por sus respectivos gobiernos, Regionales o Nacionales, como seguidamente comprobaremos. 
De todo lo visto, podemos concluir que el control interno no solo es una actuación concreta (reparos), de las personas encargadas del mismo, sino un conjunto de medidas, planes y poderes, que incluyen incluso, la posibilidad de emitir ACTOS PROPIOS DE CONTROL, con los efectos señalados en las Leyes, debiendo incluir también la POSIBILIDAD de dirección, organización y planificación de la propia función de control, dentro de la entidad, por lo que la definición, del informe Coso, solo como un proceso del personal de la entidad para el logro de unos fines», debe considerarse INSUFICIENTE, a la vista de lo apuntado y de la regulación establecida en la organización publica territorial europea, como veremos seguidamente.

\section{ASPECTOS CRÍTICOS EN LA ACTUALIDAD. ESTATUTO Y GARANTÍAS}

En España, dicha actuación de control en el sector local, viene perfilada en los Art. 194 a 203 de Ley 39/88 Reguladora de las Haciendas Locales, (LRHL) pero aún reconociendo, que la misma en este aspecto, supuso un importante avance respecto a formulaciones anteriores, al existir un reconocimiento legal y constitucional de la importancia de dichas tareas ${ }^{35}$, tanto en lo que suponga satisfacer, una necesidad de las propias entidades, que demandan ese control, como en lo que afecte a los gobiernos Regionales o Centrales, que ven en el control interno local, una garantía en la aplicación de los objetivos generales de los servicios públicos; sus efectos sin embargo, han quedado muy cercenados y limitados, por varios motivos.

Entendemos en primer lugar, que de las cuestiones planteadas en el apartado anterior, para garantizar un eficaz control interno, en las entidades y organizaciones, únicamente su definición, como función de control en el ámbito público, es acertadamente considerada en la LRHL, si bien el concepto de control interno no ha sido correctamente desarrollado reglamentariamente en el ámbito local, al no recoger una definición extensa del mismo, pues en su delimitación se considera incluido o subsumido, en sus acepciones usuales, por lo que estas se encauzan de una forma muy intensa, hacia dicho aspecto operativo, centrándose en los aspectos de ejecución del mismo, mediante el ejercicio de la función Interventora, o en la aplicación concreta, del control de eficacia o del control financiero. Pero de forma desligada del resto de consi-

\footnotetext{
${ }^{35}$ Para J.L. Pablos RodRíGueZ en, «Gestión e Información contable en las entidades locales» Ed. ICAC. 1997, p. 307 y ss. «La formulación que realiza la Ley de Haciendas Locales, debe considerarse acertada, pues es la primera vez que se regula el control interno en los entes locales, atendiendo a sus facetas, lo que supone incorporar a dicha entidades a un mismo marco legal, que tiene su fundamento en la Constitución y en la Ley General Presupuestaria».
} 
deraciones, que ya hemos visto: medios, organización procesal, estatuto de garantias, relaciones con el control externo, aspecto dual de las funciones de control interno, etc. Lo que produce un efecto limitador, que debilita muy seriamente su resultado, al carecer de una base cierta y positiva, para apoyar unos efectos concretos y predeterminados, que no se queden, en los meramente enunciativos, y que son imprescindibles en toda función de control.

En este sentido, otro motivo que comentan diversos autores, que limita la actuación del control, es aquella que consideran implícita en la definición de la LRHL, de que el control interno ejercido de "forma previa», mediante la fiscalización, debe reorientarse hacia el control financiero «a posteriori», cuando ambas son dos actividades complementarias y no excluyentes, sobre todo, desde el RD. 2188/95. Motivo por el cual, la potenciación de la auditoria a posteriori, no debe nunca implicar, una limitación de las facultades, ni de los efectos, de la fiscalización preventiva o previa, mucho más importante en la gestión local actual.

Otra limitación de la legislación, que se hecha en falta en la administración local procede de la expresión literal, recogida en la LRHL, de que la fiscalización se realiza «con la extensión y efectos que se determinan en los artículos siguientes» del art. 194, y dado que hasta la fecha no se hay desarrollado el mismo. Esto ha limitado y condicionado los efectos prácticos del control, puesto que se ha concentrando, en unas valoraciones o actuaciones concretas y en una persona determinadas, encargadas de ejercer el mismo, pero sin unas bases legales o reglamentarias estables apropiadas y jurídicamente objetivas ${ }^{36}$. El efecto fundamental de esta inacabada regulación, es la generación de un hábito incorrecto en el órgano gestor, que en la confusión de funciones, al carecer de normativa o aplicar supletoriamente la normativa estatal, evita cómodamente la realización correcta de su gestión o del expediente que implica gastos, esperando que sea el control interno o judicial, el que enmiende, componga o en su caso, corrija, mediante el reparo o la sentencia, la defectuosa tramitación realizada, incluyendo la gestión de los gastos y pagos que conlleve. Como vemos el control interno legalmente en España, se identifica con una actuación concreta de unas personas, que tienen la misión de vigilancia del sistema, pero en muchos casos, sin que la legislación haya articulado los ins-

\footnotetext{
${ }^{36}$ En el control financiero como ha puesto de relieve G. MAÑEZ VINDEL, «los datos obtenidos del control, deben dar lugar a un fenómeno de retroalimentación dirigida a la mejora de la gestión, para lo cual el órgano controlador, no solo debe poner de manifiesto las deficiencias, sino que debe formular propuestas de mejora, y el órgano gestor aceptarlas o argumentar su inadecuación». En «El modelo de control interno de la Actividad Económico Financiera del sector Público Estatal». Presupuesto y Gasto Público, n. ${ }^{\circ} 18$ (1996). p. 36.
} 
trumentos necesarios para su ejercicio, sin haber determinando los medios acordes, a los fines perseguidos o se hayan standardizados los necesarios, según la entidad o necesidades de las corporaciones, con una garantías funcionales de independencia objetiva según el Art. 203, pero sin, una concreción de las mismas, a los efectos prácticos, ante los posibles incumplimiento de normas sustantivas y de las actuaciones del control. Así, como fundamentalmente en la carencia del cauce procesal interno y organizativo de la entidad, en donde se debe incardinar la función de control, por lo que muchas veces, son realidades contrapuestas. Y por supuesto, sin conocer y determinar los efectos concretos de los informes y reparos escritos de la Intervención municipal, que en la mayoría de los casos, quedan arrollados, por las mayorías políticas en la actuación ordinaria, al carecer de efectos punitivos o disuasorios reales, o cuanto menos paralizantes, de las irregularidades, por más que la Ley establezca esos efectos suspensivos de los reparos, hasta que el Pleno resuelva.

En resumen, una vez manifestada, la necesidad de control de la actividad financiera local, al haber encontrado fundamentos suficientes, para ejercer el control, tanto por fórmulas internas, como externas, y en el aspecto interno, tanto por ser una necesidad de la propia organización local, como por ser una finalidad impuesta por normas o instancias estatales, que también requieren, un ejercicio del control interno en los entes locales, en beneficio de las políticas supra-municipales, resaltando por tanto el «carácter bifronte» de las mismas. Habiendo encontrando en España, que la misma tiene importantes debilidades, que ha sido ampliamente criticadas, en términos parecidos a los hasta aquí comentados, entre otros por: Rubio de Urquía y ARNAl SuRIa ${ }^{37}$, Arnau Bernia ${ }^{38}$, Aragón SÁncheZ $^{39}$, Fuentes Vega ${ }^{40}$ o De Prado Alonso ${ }^{41}$.

Resumiendo por tanto, con dichos autores los problemas del estatuto funcional y de garantías del control interno local, en los siguientes problemas, para el ejercicio del mismo:

\footnotetext{
37 Rubio de Urquía y Arnal Suria, «La Ley de las Haciendas Locales». Ed. El Consultor. Madrid. 1996, pp. 1245.

38 V. ARnau Bernia, «Los Interventores de la Administración Local y las funciones de control interno». Rev. de Hacienda Local, n. ${ }^{\circ}$ 72, Ed. Edersa. Sept- Dic. 1994.

${ }^{39}$ C. ARagón SÁncheZ, «Funciones directivas de las entidades locales. Desafíos y Futuros.» Rev. El Consultor de los Ayuntamientos, n. . 23, Diciembre 1997.

40 S. Fuentes Vega, «El Control Interno» En la obra colectiva «Control del sector público». Ed. I.E.F. Madrid 1981.

${ }^{41}$ R. De Prado Alonso, «El control interno de la gestión económico financiera de las entidades locales», Cuadernos de Administración local. Comunidad de Madrid, 1999.
} 
- Falta de un estatuto de garantías para el ejercicio independiente, dentro de las entidades locales, de las funciones de control, como desarrollo, del enunciado del Art.203 de la LHL.

- Excesiva Dependencia orgánica y jerárquica del Alcalde-Presidente, siendo estos a la vez los máximos órganos gestores fiscalizados, con importantes atribuciones resolutivas, en el estatuto de garantías personales, en aspectos: retributivos, sancionadores, carrera profesional, etc. Aspecto este muy limitativo del control, puesto que por la naturaleza de ambas tareas, lo lógico, es que sean órganos encontrados, como el poder ejecutivo y el judicial.

- Limitaciones al control, por la dependencia total de las Corporaciones, en aspectos de organización del servicio interno, tanto de medios personales, como materiales, incluida la informática, como en la definición de la estructura de la organización municipal, para implantar un sistema de control o de procedimientos, para el ejercicio del mismo.

- Imprecisión normativa y reglamentaria, sobre los efectos de los informes del control financiero, que debe considerarse más bien, como un desajuste intencionado del sistema establecido legalmente, que como un olvido, dado que no esta determinado por la Ley, después de 15 años, ningún efecto sancionador o cuanto menos corrector, de cara al futuro, de las conductas denunciadas en los mismos.

- A parte del carácter muy limitado del reparo local de forma previa, por la falta de un cauce procesal efectivo para la resolución del mismo, y por la naturaleza propia de la organización local, con un componente cada vez más político, (Alcalde, Pleno) muchas veces sin capacidad y conocimiento suficientes, para la resolución de las cuestiones, muy técnicas, que plantea un reparo, ya sean jurídicas, económicas o financieras.

\section{EL CONTROL INTERNO EN EL DERECHO LOCAL EUROPEO}

A la vista del expuesto, vamos a hacer una aproximación a las funciones, medios y garantías que sobre el control interno local, se han establecido y se realizan en otros países de nuestro entorno, fundamentalmente de la Unión europea, considerando con mayor profundidad el modelo de control interno local continental, sometido al derecho administrativo, cuyo expo- 
nente más relevante, sería el caso de Francia, en comparación al otro gran modelo, de los países de la órbita anglosajona, que siguen en Inglaterra o Irlanda. Por proximidad, también efectuaremos unas reflexiones sobre el modelo italiano, que si bien, basado en la tradición continental, ha introducido, desde los años 90, figuras de control de la dinámica sajona, y que la doctrina actual viene criticando, en su efectividad, al presentar unos resultados muy limitados y poco efectivos, como instrumentos de control interno. En todos los casos, Hay que resaltar al hablar del control interno en Europa, que obligatoriamente debemos referirnos de forma conjunta, también al externo, por la amplia e imbricada relación establecida legalmente entre ambos, en algunos casos muy díficil de separar ambas realidades.

\section{VI.1. El sistema de control local de Inglaterra y Gales}

En principio debemos comentar, que nos referimos al sistema de finanzas locales de Inglaterra y Gales, por cuanto Escocia e Irlanda, con instituciones muy semejantes, cuentan con una normativa propia, que pudiera diferir. Por lo que comentamos brevemente este modelo, haciendo antes unas breves anotaciones, sobre la administración local inglesa, por cuanto tiene unas características propias, basadas en la tradicional organización de los servicios públicos, o «Self government« local inglés. Principios, que con Jiménez Blanco ${ }^{42}$, podemos resumir:

- El gobierno Inglés no tiene, una organización periférica, ni permanente, ni eventual, por lo que la ejecución y gestión de sus servicios públicos, se realiza por Agencias Nacionales.

- El gobierno carece de vocación ejecutiva, por lo que la aplicación de las políticas, se encomienda a la administración territorial, ya sean condados o municipios.

- La gestión por tanto local, tiene una marcado carácter ejecutivo y práctico, no político y por ello, esta sustentado sobre las directivas y reglamentos nacionales o del propio ente, que es la que deben aplicar y gestionar los técnicos (Officials) y demás personal municipal.

- Las entidades locales se han configurado en la tradición Jurídica inglesa, como entidades estatutarias, sometidas al régimen legal

42 A. JimÉnEz BlAnCO, «La organización local Inglesa», Documentación Administrativa. 228. OctDic 1991. 
común, de cualquier entidad con personalidad jurídica propia, como una Sociedad Anónima, por lo que están muy limitadas en su actuación, por los principios generales del ordenamiento: Rule of law, Ultra vires, etc.

- Las principales notas y características del sistema de control y gestión financiera local Inglesa, las podemos compendiar en las siguientes características:

$\left.1^{\circ}\right)$ La nota principal de la administración financiera local inglesa, estribaría en la obligación de mantener ciertos fondos, para ciertas transacciones. Esto no solo supone una facilidad para el sistema de auditoria externa, sino que es también, una facilidad en el control del gasto público. El sistema de los fondos, ha dado origen a una contabilidad propia y a un peculiar sistema registro de los mismos, incluso a formas de anotar y de rendir de cuentas y estados contables, adaptados a dicho sistema, y que incluyen sistemas de control, interno y externo e incluso el estatuto del personal de finanzas, según la reglamentación nacional y de la propia entidad.

$2^{\circ}$ ) En este sentido, debemos destacar, que la entidad local, dentro de su «autonomía» esta obligada a regular y reglamentar, en sus propias ordenanzas, los aspectos financieros y de control, para asegurarse que el Official, designado de la gestión de las finanzas, que actúa como agente del committe, (No es un político, sino un profesional) asume y cumple esta responsabilidad. (Esta obligación implica, la gestión total de la actividad financiera, con firma de contratos, decisiones de gasto, convenir, dirigir, etc.). Aquí queremos señalar la evolución reciente de esta figura (Chief Finance Official), pues igual que ha ocurrido, con el nombramiento de oficial jefe de policía o de incendios, este ha pasado ha ser, una competencia del Gobierno Central, como fórmula para garantizar una cualificación y uniformidad de dichos miembros en todas las entidades, así como su independencia de cualquier partido político. El oficial jefe de finanzas, como se denomina, también a veces, Tesorero, debe estar cualificado por una de las corporaciones profesionales de contabilidad de Inglaterra. Teniendo una particular responsabilidad personal y profesional, en los sistemas de control, de gestión y rendición de cuentas, desde la publicación de la Local Governmnet Act de $1988^{43}$.Por nuestra parte, queremos resaltar, que esta formulación, se aparta de la tradicional regulación de los nombramientos del personal municipal. Justificando la misma, por la necesidad de ejercer un mayor control, ante la dispersión y multiplici-

43 C. GonZÁlez Álvarez, «Las vicisitudes del derecho local en Inglaterra y Gales». REALA n. ${ }^{\circ}$ 260.Octubre 1993. pp. 851. 
dad de entidades locales, y que ha inducido, también al legislador inglés, a buscar y ampliar las figuras de control, con fórmulas similares a las continentales, para poder así, satisfacer dicha necesidad de información y control de la actuación local, previniendo, en parte los costes y daños, que sobre sus propias políticas, la actuación local le pudiera suponer.

$3^{\circ}$ ) En cualquier caso, dentro de las obligaciones de este oficial, debemos resaltar, la responsabilidad de la gestión contable y de cuentas, así como la obligación legal, de lo que aquí consideraríamos como actuación de reparo, (report), al tener que informar por escrito, si en su opinión, la autoridad ha efectuado o va a efectuar, una acción o gasto ilegal (Unlaw$f u l)$ o toma, o va a tomar, una acuerdo que suponga perdidas o déficit ( Loss or deficiency), o si incurre en excesos o gastos, (Ultra vires)fuera de la nivelación con sus recursos. Esta es una función personal del Chief Financial Officer, debiendo remitir copias del reparo o informe, a cada uno de los miembros del comité y al auditor externo. La Autoridad o committé responsable debe considerar el informe, en los 21 días siguientes, convocando una reunión y por tanto, quedando la propuesta o resolución en suspenso, hasta la reunión, que resuelva sobre el mismo ${ }^{44}$.

El caso inglés llama más la atención si cabe, pues no solo se ha fortalecido la independencia de ciertos «funcionarios», con el nombramiento estatal, sino que la Ley ha reforzado las figuras y funciones de control, por ejemplo, en la Local Government and Housing Act, de 1988,45 se ha añadido a figura del oficial asesor, o de vigilancia, (Monitorig Official), cuya principal misión, estriba en vigilar y advertir a la autoridad y a su personal, de toda decisión u omisión que realice la misma, y que pueda dar lugar a una infracción de la ley o de sus ordenanzas internas, o que suponga un quebranto de cualquier disposición legal. Figuras que incluso, han sido consideradas necesarias, por los gobiernos posteriores ${ }^{46}$.

$4^{\circ}$ ) Por último y solo como indicación, comentar que la administración financiera local inglesa, desde que se exigieron las primeras contribuciones locales en el siglo XVII, siempre ha estado sujeta a la inspección o verificación externa, como medida de garantía y salvaguarda del empleo del dinero público. A partir de 1846, dicha tarea se organizó mediante el ser-

\footnotetext{
${ }^{44}$ S.H. BAYLEI, «Cross on principles of local Government Law». Ed. Sweet \& Maxwell. $2^{\mathrm{a}}$ Edition. London 1997.

45 S.H. BAYLEI,. «Cross on .....», op cit.

${ }^{46}$ Una valoración de la modernización publica en UK, puede verse: A. MidwINTER, « New labour and modernisation of british local government». Financial, Accountability \& Management. (F,A \& M) Oxford. Novermber 2001.
} 
vicio de los auditores de distrito, antecedente de las actuales Auditorías, de la Audit Commission.

En principio dicho sistema desde 1982, esta basado en el concepto de Auditoría que todos conocemos, implicando que una vez nombrados los auditores, estos actúan con total independencia de los políticos y de otras personas, con intereses en las entidades. La Audit Commissión, para los gobiernos locales, de Inglaterra y Gales, como organismo estatal independiente, garantiza el control sobre el sistema, así como el resultado, pues junto con los auditores, y de acuerdo con un código reglamentario, efectúan comprobaciones sobre la calidad de las mismas. La comisión es independiente, sé autofinancia con las tasas y honorarios, que recauda de los servicios que presta, y no recibe subvenciones del gobierno. Desde 1992 incluso con obligación dar publicidad, a los estados de cuentas de las entidades locales.

En este sentido la Audit Commission, tiene como objetivo ayudar, a las entidades locales a mejorar los servicios públicos de su competencia, promoviendo la mejor custodia y administración de los recursos públicos, ayudando a las entidades locales a generar eficacia y eficiencia en los servicios, o cuanto menos, evitando el despilfarro. La comisión, tendría cuatro grandes misiones: a) Nombramiento de todos los auditores de las entidades locales. b) Regular y emitir recomendaciones, a través del código de práctica de la auditoria. c) Efectuar estudios a nivel nacional para la mejorar de los servicios públicos y d) Idear y definir indicadores de todo tipo, que publicados, sirvan para la comparación de los resultados entre las entidades locales.

Las funciones y obligaciones fundamentales de los auditores miembros, serían:

- Comprobar que las cuentas locales, están correctamente preparadas, de acuerdo con las regulaciones legales u demás normas y previsiones establecidas y obligatorias.

- Que las normas contenidas en las propias ordenanzas y reglamentos locales, han sido observadas en la confección de las cuentas, asegurándose que la gestión pública es conducida de acuerdo con la ley y las normas propias, y que el dinero público, esta debidamente protegido, y es registrado siempre en los estados y cuentas.

- Que la entidad ha efectuado, los ajustes y actuaciones, para asegurarse la economía eficacia y eficiencia, en el uso de los recursos públicos.

- Que la entidad a cumplido con las obligaciones de publicidad impuestas por las normas, para ello, el auditor tiene que obtener evi- 
dencia escrita u oral de los aspectos más importantes de las cuentas, de acuerdo al código y a las técnicas propias de este sistema de investigación inquisitiva.

Por último remarcar, que los auditores de las entidades locales inglesas, tienen unos poderes especiales, recogidos en el apartado $1^{\circ}$, del Código de práctica de la Auditoria Local y que consisten, más en una responsabilidad, que en un derecho, pues basado en el principio de Fiducia o confianza del vecindario en su tarea de control, en la revisión que efectúen en las entidades locales, están obligados, por ejemplo, como el oficial de finanzas, a impedir primero paralizando la acción ilegal, que quiera llevar a cabo, una entidad, sus agentes o personal y segundo a reclamar ante la justicia ordinaria, una declaración o una sentencia, condenatoria contra el autor de tal actuación ilegal. La valoración no solo se realiza por infracción de la ley, sino por conceptos más amplios, como mala administración o administración irrazonable o dañina para la entidad. Los auditores, cuentan con la posibilidad de repetir, exigir o recargar, el importe o la suma que de forma ilegal o fuera del mandato conferido, se haya podido utilizar, es decir, cuando se considere un gasto "ultra vires» que debe ser reintegrado, siendo misión del auditor el proceso de su cobro ${ }^{47}$.

\section{VI.2. El control de la gestión financiera local en Francia}

Como ya hemos comentado anteriormente, en este trabajo, «La Declaración de derechos del hombre y del ciudadano» de 1789, establece en su artículo 15, que el pueblo francés tenía derecho a exigir o demandar, la rendición de las cuentas de la administración, que realiza todo agente o gestor público. Sobre este principio se construyó, todo el sistema de control y rendición de cuentas públicas, en Francia, que en la actualidad podemos resumir, en tres tipos:

a) El control interno, como grupo de mecanismos que garantizan a priori, la regularidad y la conformidad, de las autorizaciones y las realizaciones presupuestarias, tanto de los ingresos, como de los gastos, correspondientes de un organismo público.

b) El control externo, de la gestión financiera de los organismos públicos, que es ejercido por una institución independiente e imparcial,

${ }^{47}$ Algunas sentencias en: M. CuCHILlo FoiX, «La reforma del régimen Local en Inglaterra y Gales». IEAL 1987. 
pronunciándose a posteriori, sobre la regularidad y la buena gestión, incluso con poder jurisdiccional o semi-jurisdiccional.

c) El control político, que es ejercido por los electores periódicamente sobre los electos y por las asambleas deliberantes, sobre la gestión de estos. En cualquier caso, estos tres controles, forman un sistema o conjunto de control, que desarrollamos brevemente.

$\left.1^{\circ}\right)$ El control interno, cuenta con una larga tradición en la República Francesa, desde su implantación al principio del siglo XIX, la finalidad del mismo, es ejercer un control permanente sobre la actuación y realización, de todos lo cobros y pagos de la entidad local, garantizando su regularidad y su adecuación a las normas. Para ello, se creó un cuerpo especial de control, el de los «comptables publics», como funcionarios independientes $^{48}$ y liberados de la autoridad de los ordenadores (que suelen ser electos), respondiendo en todo momento al principio de separación de poderes, como fórmula de control, entre los actores de la gestión financiera local. Al elaborar las cuentas de los organismos públicos, los contables públicos, son jurídicamente responsables de que el contenido refleje la realidad de la gestión, es decir, de la calidad de las cuentas, así como de la regularidad del contenido de las mismas, pudiendo ser sancionados, si en las mismas se incluyen, errores, infracciones, fraudes o irregularida$\operatorname{des}^{49}$.

Los contables públicos son ante todo, los que deben efectuar los cobros y pagos materiales de la entidad y confeccionar las cuentas, en tiempo real, reflejando fielmente las gestiones que realizan los ordenadores y de esta forma contribuyen a un control social permanente, basado en la fuerte relación que existe, en las entidades y establecimientos públicos locales, entre la ejecución y su control, siendo a la vez, los que aportan una garantía de calidad a la misma, y una ayuda precisa, tanto a los electos, como a otros funcionarios locales.

En este sentido el control interno de las entidades locales francesas, presenta unas notas de uniformidad e igualdad, al establecerse un procedimiento interno similar, para comprometer y autorizar gastos e ingresos, así como la determinación clara y universalmente aceptada, de cual deben ser las justificaciones de los mismos, en todas las entidades, implicando también la llevanza y registro de una contabilidad apropiada, y que faci-

\footnotetext{
48 Una idea más amplia en Jacques Magnet, Les Comptables Publiques,. L.G.D.J. Paris 1995 y en: AdAms, Boyer y LAURent, «La Comptabilité communale». LGPJ. Paris 1998.

49 JB. Auby JM-AuBY, «Institutions Administratives». Ed Dalloz. Paris 1996.
} 
lita el conocimiento y aprendizaje a los usuarios de la información, en todas las partes del territorio francés. Por otro lado, el sistema se ha mejorado recientemente, al introducir la necesidad de controlar el funcionamiento de las estructuras de gestión de la entidad, incluidas empresas u organismos autónomos, los denominados satélites, y con obligación de consolidación, así como, por el análisis financiero y de ratios, como forma de valoración patrimonial, y de la calidad del resultado en cada entidad.

$\left.2^{\circ}\right)$ El control externo de la gestión local, es realizado mediante el examen de la gestión de los ordenadores, por la Cámara Regional de Cuen$\operatorname{tas}^{50}$, de forma paralela al juicio de cuentas, que deben rendir los contables públicos. La característica esencial de este control, es que es sistemático y cíclico, es decir, se hace de acuerdo a un programa o lista de puntos a revisar y de media, cada cuatro años, se deben revisar todos los Ayuntamiento y entidades locales.

El examen que efectúa la Cámara de Cuentas Regional, consiste en la comprobación de la regularidad y de lo que se llamaría la «buena gestión». La primera comprendería la regularidad contable, que por decirlo de forma sencilla, sería una competencia del contable público, sin embargo, la propia contabilidad al reflejar la gestión, comprobaría la regularidad de las actuaciones del ordenador, por ejemplo, en materia de ejecución de gastos públicos, como del cumplimiento de los códigos de actuación, las reglas de los mercados, de la legislación de funcionarios, o del régimen de contratación laboral o en materia de obras públicas, etc. También las cámaras comprueban las realizaciones y contrataciones plurianuales. En todo caso, las deficiencias y faltas se materializan en unos informes de la Cámara, con recomendaciones y observaciones que son públicos y pueden incluso, suponer medidas de reintegro de fondos.

El control de regularidad, no supone necesariamente la buena gestión de los servicios locales. Esta implica comprobar que la entidad cuenta con los mecanismos necesarios, para detectar e informar, de los cambios y desviaciones, cualitativas del presupuesto o de la gestión, de tal manera, que se puedan tomar las decisiones oportunas. Es decir, que el sistema instalado, para facilitar información, garantiza una rápida posibilidad de corregir y enmendar los fallos o errores. La cámara examina ${ }^{51}$ por tanto, el sistema de control interno de la entidad, tanto, como los datos que del

\footnotetext{
50 JB. AuBy JM-AuBy, «Institutions Administratives». Ed Dalloz. Paris 1996. $7^{\circ}$ Ed. pp. 173.Tambien, en A. FANLo LORAS, «El Tribunal de Cuentas y las Corporaciones locales»IEAL. Madrid. 1986.

${ }^{51}$ GohIN Olivier, «Institutions Administratives». Ed. L.G.D.J. Paris 1998.
} 
mismo, se obtienen. Una vez comprobado el control interno como sistema de información, la cámara repasa, si la gestión, ha sido eficiente y eficaz económicamente. Así, se supone que la falta de control en la gestión financiera, es una gestión ineficaz, también cuando se multiplican las estructuras paralelas, para el funcionamiento de un servicio. En cuanto a la medida de la eficiencia, se plantea siempre el conflicto, entre la oportunidad política de una decisión y la cuestión de su eficiencia, y que ha desembocado en el sistema local francés, en la necesidad de establecer unos indicadores claros y sencillos, que son calculados de forma homogénea, para medir dichos conceptos, de tal manera que gastar por gastar, o la propia «gestión de hecho», son indicadores contrarios a la buena gestión.

$\left.3^{a}\right)$ Como último componente dentro del sistema global de control, debemos citar, El control Político, que ejercen las asambleas y plenos municipales, dado que estos tienen importantes competencias en las aprobaciones y autorizaciones, por ejemplo, del presupuesto anual o de las cuentas de la gestión realizada, e incluso la posibilidad de solicitar la intervención de la Cámara Regional de Cuentas, como fórmula de control, por ejemplo, para la nivelación de déficits importantes, e incluso la del Prefecto, en lo que se considera que es, un control financiero popular ${ }^{52}$. Por otra parte, las entidades locales deben facilitar a los vecinos información, del presupuesto, cuentas e imposición local, para su examen, así como, de entidades, organismos y empresas propias gestoras de servicios públicos. Y ello, como medida para facilitar la transparencia y el control, a los miembros del vecindario de las mismas. Incluso las Cámaras de Cuentas deben publicar los informes de fiscalización, que realizan a los entes auditados o revisados, para forzar a la mejora de la gestión, corrigiendo así las deficiencias, y forzando una gestión transparente y el cumplimiento de los derechos, que asisten a los vecinos.

\section{VI.3. Controles locales internos en Italia}

Las funciones de control interno en Italia, tienen un doble sentido, según el Texto Único de los entes locales, n. ${ }^{\circ}$ 267, de 18 de Agosto del 2000. (En adelante, TU) Pues sus Arts. 152 y 242, hablan de las fórmulas de control, que venimos exponiendo, referentes al control interno, de la ejecución presupuestaria y la reglamentación vigente, mientras que el control de eficacia y eficiencia en los resultados, se recogen en el art. 196

${ }^{52}$ M. BouviER, «Les Finances Locales» L.G.D.J. Paris, 1999. 
y ss., como control de gestión. En cualquier caso, el sistema Italiano, responde al sistema continental, de base Francesa, si bien en Italia, se han introducido variaciones, intentando reforzar el control interno, mediante la figura del Revisor o Auditor contable, pero que en estos primeros años, no ha obtenido los efectos que pretendía ${ }^{53}$. En este análisis, debemos establecer en primer lugar, que la Constitución Italiana, reconoce a los entes locales, autonomía para la gestión de sus intereses, aunque esta, debe ejercerse siempre, dentro de la Ley, existiendo diversos instrumentos para garantizar su cumplimiento.

\section{Comités Regionales de Control (CORECO)}

Son órganos compuestos por miembros y personalidades con un gran conocimiento jurídico, como ex-magistrados, ex-alcaldes y similares, teniendo como misión, el control preventivo de legalidad de ciertos actos locales. Por ello, los entes locales deben remitir de forma previa a su aprobación, ciertos acuerdos, que solo pueden ejecutarse, cuando cuentan con la conformidad del CO. RE. CO. En la actualidad, los principales actos sometidos a este control, serían:

- Las adquisiciones, enajenaciones, arrendamientos de bienes inmuebles y en general los contratos, a suscribir por la entidad.

- Las ayudas, retribuciones, indemnizaciones, reembolsos y demás exacciones y beneficios de las autoridades, empleados o terceros, con los que se relacione el ente.

- Los actos de selección de personal, así como sus estatutos, convenios y similares.

- El presupuesto anual, y los reglamentos de impuestos e ingresos municipales, también debe ser sometidos. Desde 1999 ha disminuido su ámbito, en favor del control interno ${ }^{54}$.

Aparte del CORECO, las leyes de ordenación local, establecen otros tipos de control, sobre la actividad financiera, así, por una parte se regu-

\footnotetext{
${ }^{53}$ R. MUSSARI, «Italian municipal Audit..Half a reform?» Financial Acountability \& Management. Oxford .May 1995, también en A. PROSPERSI, «Manuale di contabilitá e balance degli enti locali». Il sole 24 Ore. $4^{\circ}$ ed. Milano 2001. Un resumen de ciertos fallos de auditoria en el sector público en A. LevitT, «E1 Mundo» 21/I/02. (Caso ENROM).

${ }^{54}$ P. VIRGA, «Diritto Amministrativo».... op. cit.
} 
lan las funciones de control interno, divididas entre el personal de la entidad y el Colegio de Revisores Contables, y de otra, la fiscalización externa, de la Corte o Cámaras Regionales de Cuentas.

\section{El Servicio Financiero y de Tesorería}

Como servicio obligatorio de cada entidad, se deben regular en los reglamentos contables propios, adaptando a su organización interna, la normativa general, como es el Texto Unificado de Agosto 2000. El servicio financiero y contable, a parte de estas nuevas obligaciones, debe mantener el tradicional control de regularidad presupuestaria, que se realiza por el funcionario de la entidad encargado o responsable de la contabilidad, pero en contacto permanente con el Colegio de Revisores. Compete al mismo, dar el visto de regularidad contable, (toma de razón contable), manifestando la existencia de crédito presupuestario, según las propuestas que realizan los distintos servicios. Dicha actuación es obligatoria para estos, al gestionar un gasto. Con ello se pretenden asegurar, que se han realizado los procedimientos y que los acuerdos, se han tomado correctamente, dentro de la Ley. El funcionario encargado, debe reparar la actuación propuesta, por falta de presupuesto, su informe debe ser remitido a los Revisores externos, al Secretario y al consistorio, en la persona de su Presidente, siempre que suponga un perjuicio para el equilibrio presupuestario. (Art. 153 y 193 T.U.) Entre la gestión contable interna y los Revisores externos, rige la necesidad de mantener la máxima información mutua.

\section{El Colegio de Revisores de Cuentas}

La Ley de la Autonomía Local Italiana de 1990, introduce esta nueva fórmula de control, que ha renovado la anterior estructura de revisión de cuentas, que realizaban los propios concejales, desde los años treinta. La Ley ha querido resaltar la importancia de esta institución de una parte, realzando la importancia de la independencia de los miembros, que con este método se ha querido mejorar, y de otra, incrementando la cualificación, que los mismos. En la actualidad, ninguno de los dos objetivos sé esta cumpliendo, por las lagunas y fallos que presenta, al considerarse, este sistema un híbrido, entre el francés y el inglés, por lo que, como mecanismo de control, ha resultado poco eficaz ${ }^{55}$.

\footnotetext{
55 A. Prospersi, «Manuale di contabilita e Bilanci degli enti locali». Il sole 24 ore. Milano 2001.
} 
El colegio de revisores esta compuesto, en los municipios de más de 5000 habitantes por tres miembros, elegidos por el Pleno Municipal. Uno, del Colegio de Auditores, otro, del Colegio de Economistas y otro, del de Jurídicos y Mercantiles. Es un órgano de cualificación técnica, si bien, es elegido por los órganos políticos. Deben registrarse como Revisores, en un Registro del Ministerio del ramo, para garantizar, el régimen de incompatibilidades y la independencia, en la actuación. Los revisores son incompatibles, con otros cargos y con el de concejal o electo. Su mandato normal de revisión, es por plazo tres años, pero hay prórrogas. La Ley reglamenta también, el sistema de retribuciones, para garantizar su independencia, de cara al cumplimiento de ciertas funciones de raíz estatal y la salvaguarda de la actividad de control ${ }^{56}$.

Las principales funciones del colegio de revisores, serían:

1. La vigilancia e inspección contable y de la actividad financiera, para comprobar la regularidad y veracidad de la misma, controlando la realidad de las anotaciones y cuentas, de tal forma que dichos estados respondan, a la imagen fiel de la entidad. Se resume en unos informes de la liquidación presupuestaria y de las cuentas a rendir.

2. Control de actos singulares, no solo debe garantizar la regularidad de las partidas presupuestarias, sino que además, debe en caso de graves irregularidades o en la falta consignación presupuestaria, avisar al consistorio (attivitá di referto) y si existe daño al erario, denunciarlo a la Corte de Cuentas. Con responsabilidad penal, al considerar al revisor como un mandatario del Pleno, con la responsabilidad propia de un funcionario.

3. Tiene también una tarea consultiva, pues los informes de la liquidación y del presupuesto deben contener, aspectos para la mejora de los resultados económicos y de control de costes, empleando indicadores para comparar la actuación realizada. En este aspecto, vemos acertada la crítica que efectúa TowLEY ${ }^{57}$, ante la actual hiperinflación y falta de consistencia, de muchos de los indicadores que se presentan.

\footnotetext{
56 B. Dei, R. Giacinti, P.R. Sorignani, E. Terzani, «Il Revisore degli enti locali». Il sole 24 ore. Milano 1998.

${ }^{57}$ B. TownLey, Cifra en 4000, los indicadores escolares de Inglaterra, «The cult of modernity», F.A.\&.M. Nov. 2001.
} 


\section{La Federación Alemana y el control de las entidades locales}

Tras la reunificación de 1990, entre las dos Alemanias, la estructura regional de la administración pública, se divide en 16 Landers o Estados federados, que incluyen unos 542 kreise o distritos, para la prestación de servicios públicos y aproximadamente, unos 16.000 , municipios y ciudades, donde más de 90 de ellas, superan los 100.000 habitantes. La estructura federal, hace que los Landers tengan una gran importancia, en la configuración de la administración local, pues si bien la Federación Estatal, es la que tiene la competencia del diseño económico y de la función legislativa, su ejecución corresponde al Lander. Motivo por el cual, la relación de los entes locales con el Lander, es muy estrecha ${ }^{58}$.Los Landers tienen también en algunas materias, amplias competencias legislativas y reglamentarias, sobre todo las referentes, a la vigilancia de los servicios que prestan las entidades locales.

Otra de las características intrínsecas de la organización territorial alemana estriba, en los diversos tipos, que podemos encontrarnos de la organización interna municipal, (hasta cuatro) si bien, esta cada vez más coordinados, dentro del llamado federalismo cooperativo de la República Federal. Que implica, una superioridad de la norma federal, sobre la del Lander, la obligación de lealtad al mismo, así como la necesidad de coordinar la actuación económica a los planes y directrices marcados a nivel superior, aunque, las entidades locales cuentan con una amplia autonomía histórica para la organización, de sus instituciones, que la federación y los Landers, deben respetar, pero dentro de la superioridad de la Ley Federal ${ }^{59}$ Entre los tipos de organizaciones municipales, citamos la organización del Consejo del Norte, con una figura de Burgomaestre más honorífica, sobre la gestión de los funcionarios. El modelo de Magistrat. La del Consejo del Sur, donde el Burgermeister ejerce de titular de los servicios locales y por último, el Régimen del Burgermeister de elección por el concejo, de Renania-Palatinado.

En cuanto al control, los entes locales alemanes, están sometidos a un control jurídico por parte de los Landers, que es incluso, un control de oportunidad, cuando las entidades realizan alguna actuación por delega-

\footnotetext{
58 No en vano, SOSA WAGNER comentaba necesidad de utilizar permanentemente el sistema de comunicación, entre el gestor del municipio y el órgano de control del Lander, en «La Autonomía Local» REALA, n. ${ }^{\circ} 230-240-241,1988$.

59 GonZÁLeZ VARAS-IbÁÑEZ, «La organización municipal Alemana». Documentación Administrativa, n. ${ }^{\circ} 228$. pp. 257.
} 
ción o dentro de la coordinación necesaria, que debe imponer el Lander, por ejemplo, en las elecciones, o de política económica general. Y por supuesto, en ejecución de aspectos de planificación, dentro de la política económica y de presupuestos que aprueba el Lander o la Federación, existiendo órganos encargados de su vigilancia y coordinación como son el Consejo de Planificación Financiera o el Consejo de Cumplimiento Presupuestario. La aprobación del presupuesto municipal y el control de la deuda, de los entes locales, por el Lander, tienen una especial consideración $^{60}$.

En el aspecto de control interno en Alemania no existe, ni en el ámbito estatal, ni local, lo que podríamos considerar interventores, dependientes del Ministerio de Hacienda, pues en principio el control externo del Tribunal de Cuentas Federal o Estatal, es el que tiene prevalecida, al asumir mayores funciones y competencias, que las habitualmente conocidas en el resto de Tribunales de Cuentas Europeos ${ }^{61}$.

La gestión presupuestaria en las entidades, se encargaría a unos empleados cualificados o especialistas, pero dentro de la propia organización municipal, que como ya hemos visto, varia ampliamente de unos estados a otros, por lo que no se puede generalizar, dado que en algunos de estos empleados, dependen de electos, pero en otros, de profesionales encargados de la gestión, en cualquier caso, su misión es muy técnica, exclusivamente de comprobación de la regularidad del presupuesto, en cuanto al registro de a cobros y pagos, dentro de sus partidas.

Existirían sin embargo otras figuras, más uniformes en toda la administración pública alemana, que serían los Encargados del presupuesto, dentro de las oficinas de presupuestos y que dependerían funcional y técnicamente, de los Tribunales de Cuentas o del propio Tribunal Federal. En Alemania cada Lander, tiene su propio Tribunal de Cuentas y existe otro en el ámbito nacional. Este personal, aunque desarrolla la misión en la entidad local o en el Ministerio correspondiente, depende del Tribunal de Cuentas, con ello, se intenta dar una independencia, similar al modelo francés, si bien, los Tribunales de Cuentas Alemanes, tienen también la misión del control del cumplimiento de las normas y directrices o reglamentos de la política nacional o del propio Lander, tanto si, las ordenes están incluidas en Leyes, de planificación, estabilización, o similares, como si solo son, directrices, instrucciones y ordenes concretas. En este

\footnotetext{
${ }^{60}$ Ruiz HuERTA y otros: «Estructura y Gestión del Gasto en algunos países de la OCDE». IEF. 1993. 27 y ss.

${ }^{61}$ RuIZ HuERTA y otros: «Estructura y Gestión del .....» op. cit., p. 32.
} 
sentido, la tarea de dichos empleados nombrados por los Tribunales de Cuentas, al efectuar el control de dicho cumplimiento, no se puede supeditar, al mandato concreto de un Alcalde o de una entidad local, sino al de la norma superior.

Las funciones fiscalizadoras se realizan por ello, bajo directrices del Tribunal, que además de la regularidad contable, tiene que comprobar, la ejecución de las políticas nacionales, de gasto y las económicas y financieras, que determine el Lander, por eso controlan ampliamente, tanto la gestión, como su planificación, ejecución y resultado. Por último como digo, resaltar que es el Tribunal, Estatal o Federal, el que nombra al personal fiscalizador, dentro de la propia administración local, para un auténtico control y ello, por lo que hemos dicho, el Tribunal externo, tiene unas misiones más amplias, que la simple fiscalización, pues en muchos casos debe orientar, de forma vinculante y comprobar el cumplimiento de la política nacional, exigiendo las responsabilidades, que en su caso, su incumplimiento, suponga.

\section{RECAPITULACIÓN Y CONCLUSIONES}

- Las actividades y funciones de control son universales y se encuentran en todas las entidades, que emplean y gestionan recursos limitados, buscando con racionalidad unos resultados, en las entidades locales, las mismas se vuelven vitales y por ello, son reconocidas en todas las legislaciones. La misión principal, del control dentro de las entidades locales, es ser una garantía de la actividad financiera pública, para mejorar su actuación, evitar fraudes, errores e irregularidades, y cumplir, dentro de los límites de la Ley, en tiempo, forma y calidad, con los fines y objetivos propuestos. Si bien, para su efectividad, se exige la posibilidad de corregir la ejecución, mediante la imposición de medidas concretas.

- La especial naturaleza del entorno público, obliga a unos sistemas de control permanentes de dicha actividad, que tienen como objetivos señalados en el presente trabajo, la formulación y rendición de cuentas por los gestores, según la esencia democrática y social de toda gestión de recursos ajenos. Otros se fundamentan, en la necesidad de coordinación y control de la política Macroeconómica, y por tanto, del control del nivel de precios, de la oferta monetaria o de nivelación de demandas, como por motivos Microeconómicos, basado en la búsqueda de una mayor eficacia en la producción de los servicios públi- 
cos, o cuanto menos, evitando los derroches que suponen los problemas organizativos, de oferta en monopolio, así como, de rendimiento de los factores y de grupos de presión, mediante un mayor control presupuestario. Por último, también hemos analizado motivos de control, por razones de la organización Constitucional de los Estados y en las necesidades legales del Estado de derecho.

- De los diversos tipos o clases de control, que se dan en las finanzas públicas, el control interno, tiene una importancia superior al resto, recientemente resaltada, por el informe COSO, que ha supuesto un revulsivo, en la concepción del mismo. En este sentido, sin embargo, varias son las limitaciones que su conceptualización se han suscitado en este trabajo, de una parte, la escasa importancia que el informe COSO, dedica a las actividades y funciones de vigilancia al definir este, más como un proceso a cumplir, sin resaltar la necesidad de la actividad especial y permanente supervisón, que el mismo requiere, para un eficaz resultado. Y por otra parte, la cuestión de que el control interno, en este caso local, no agota su cometido en la propia organización en la que se incardina, sino que tiene también, una más amplia finalidad, dada su naturaleza dual o bifronte, al justificar que satisface, tanto necesidades internas, como externas, basadas en la actividad propia del Estado de Derecho o de gestión compartida, con las CCAA.

- En España aún considerando la válida estructura del control interno, tal y como se configura en la Ley de Haciendas Locales, la misma, por la falta de un desarrollo reglamentario homogéneo, del contenido de las funciones y responsabilidades estatutarias del personal de control, que lo deslinde claramente de la gestión, así como, por las lagunas legales que la actividad de control presenta, la dependencia, en la mayoría de las actuaciones de control, del órgano gestor o controlado, en aspectos fundamentales y básicos, como son: las retribuciones, la promoción, la cualificación técnica y la responsabilidad profesional y disciplinaria, así como los medios necesarios para ejercer la misma, hacen que la calidad y contenido de los trabajos de control, estén muchas veces sesgados, cuando no directamente limitados.

- Como apoyo a las conclusiones obtenidas, hemos podido comprobar de los principales países de nuestro entorno, que las fórmulas de control interno de la actividad local son más amplias y variadas que las de aquí. En la mayoría de los Estados estudiados, el control interno satisface tanto, las necesidades internas de la propia entidad, como las externas que se plantean, por exigencias de los gobiernos supe- 
riores, bien como instrumentos adecuados para el control, de la ejecución de sus políticas globales, (Reino Unido, Alemania), bien para el control de la regularidad y uniformidad de los servicios públicos locales, en todo el territorio. (Francia, Italia).

- En los países estudiados, la actividad de control interno, tiene como misión garantizar, el cumplimiento de la legalidad y el logro del resultado fijado, por lo que se han buscado fórmulas que garanticen, la independencia real de dichos órganos de control, de los gestores locales. Así en Francia dicha circunstancia se ha solucionado, mediante el establecimiento de una estatuto especial del personal de alta cualificación, nombrado a nivel Estatal, lo que soluciona los problemas planteados. En Alemania por su parte, los encargados del control presupuestario, son miembros designados por el propio Tribunal de Cuentas, con dependencia funcional y profesional del mismo. En Inglaterra el sistema propio de la Audit Commision, hace que el personal dependa de órganos totalmente independientes, con responsabilidades estatutarias propias, no así en Italia, donde el núcleo duro del control, depende de los ejecutivos locales y por ello, son muy criticados por la doctrina, dada la falta de un juicio independiente.

\section{BIBLIOGRAFÍA}

Adams, Boyer y Laurent: «La Comptabilté communale». LGPJ. Paris 1998.

Albi, González-Páramo y Casanovas: «Gestión Pública». Ed. Ariel Economía. Barna 1997.

J.M. Auby JM-Auby JB.: «Institutions Administratives». Ed Dalloz. Paris 1996. $7^{\circ} \mathrm{Ed}$.

V. Arnau Bernia.: «Manual de Presupuestos de las Entidades locales». M. Pons. 1991.

V. ARnau Bernia: «Los Interventores de la Administración Local y las funciones de control interno». Rev. de Hacienda Local. n. ${ }^{\circ}$ 72. Ed. Edersa. Sept- Dic. 1994.

Anthony, R. \& A.Young.: «Management control in Nonprofit Organizations». Irwing Magrawhill.1999. 
C. ARAGÓN SÁnCHEZ: «Funciones directivas de las entidades locales. Desafíos y Futuros.» Rev. El Consultor de los Ayuntamientos. N. ${ }^{\circ} 23$. Diciembre 1997.

Audit Commission: «The impact of local Authoritie's efficiency of the Block Grant Distributión System» HSMO.1999.

S. BAILEY: «Local Government Economics» Macmillan. London. 1999.

S.H. BAILEY: «Cross on principles of local Government Law». Ed. Sweet \& Maxwell. 2a Edition. London 1997.

$\mathrm{F}^{\circ}$ Bohoyo CASTAÑaR: El principio de legalidad financiera como presupuesto de validez del acto $\mathrm{Ad}^{\circ}$ - I.E.F.1986.

N. Bosch \& J. SuÁrez: «Hacienda Local y elección publica: El caso de los municipios españoles» Ed. Fundación. BBV. Bilbao 1994.

Michel Bouvier: «Les Finances Locales» L.G.D.J. Paris. 1999.

CoOPERS \& LyBRAND: «Los nuevos conceptos del control interno». (COSO). Ed. Díaz de Santos. 1997.

M. CUCHILLO FoIX: «La reforma del régimen Local en Inglaterra y Gales». IEAL 1987.

David KING: «La Economía de los Gobiernos multinivel». Instituto de Estudios Fiscales. 1988.

B. Dei, R. Giacinti, P.R. Sorignani, E.Terzani: «Il Revisore degli enti locali». Il sole 24 ore. Milano 1998.

R. De Prado Alonso: «El control interno de la gestión económico financiera de las entidades locales.» Cuadernos de Administración local. Comunidad de Madrid. 1999.

J.M. Díaz Mena: «La influencia del Derecho Europeo en la actuación económica de las entidades locales». Cunal. Revista de Estudios Locales. Julio 1998.

A. Fanlo Loras: «El Tribunal de Cuentas y las Corporaciones locales» IEAL. Madrid. 1986.

S. Fuentes Vega: «La Ejecución del Gasto Público: Procedimientos y control». I.E.F. Madrid, 1994. 
S. Fuentes Vega: «El RD.2188/95, de Control Interno a ejercer por la IGAE». Revista Presupuesto y Gasto Público. N. ${ }^{\circ}$ 18/1996.

J.L. GARCÍA GARCíA: «El control interno» en la obra colectiva «Control del sector público». Ed. I.E.F. Madrid 1981.

E. GIMÉnEZ y CORRONS: «Los Controles administrativos....» Marcial Pons, 2001.

GoHIN OLIVIER: «Institutions Administratives». Ed. L.G.D.J. Paris 1998.

C. GonZÁlez Álvarez: «Las vicisitudes del derecho local en Inglaterra y Gales». REALA n. ${ }^{\circ} 260$. Octubre 1993.

GonZÁlez VARAS-IBÁÑEZ: «La organización municipal Alemana». Documentación Administrativa, n. ${ }^{\circ} 228$.

Informe Coso: Los nuevos del control Interno. Ed. Díaz de Santos. (1997).

INTOSAI: «Normas de Fiscalización y Auditoria». (1989).

A. JimÉnez Blanco: «La organización local Inglesa». Documentación Administrativa. 228.Oct-Dic. 1991.

R. Jones y M. Pendelbury: «Public Sector Accounting» Financial Time. Prentice Hall. London. 2000.

KoOntz, O'DONnell y WeIHrich: «Elementos de Administración» Mcgraw-Hill. México 1989.

J.M. LARRAINZAR GONZÁLEZ: «Función Interventora y democracia», Rev. Hacienda Local, n. ${ }^{\circ}$ 90. 2000.

A. LeVITT: «El Mundo» 21/I/02. (Caso ENROM).

M.A. Martínez Lago: «Manual de $\mathrm{D}^{\circ}$ Presupuestario». Ed. Colex. Madrid 1992.

J. Magnet: «Les Comptables Publiques. L.G.D.J. Paris.

— «Elements de comptabilité publique », L.G.D.J. Systemes. 2001.

G. MAÑEZ VINDEL: «El modelo de control interno de la Actividad Económico Financiera del sector Público Estatal».

— Presupuesto y Gasto Público. n. ${ }^{\circ} 18$ (1996). 
Monasterio y SuÁrez PANDiello: «Manual de Hacienda Autonómica y Local». Ariel Economía. Barna.1998.

A. MidWINTER: «New labour and modernisation of british local government». Financial, Accountability \& Management. Oxford. Novermber 2001 .

R. MUSSARI: «Italian municipal Audit..Half a reform?» Financial Acountability \& Management. Oxford .May 1995.

J.L. PABLOS RodRíGUEZ: «Gestión e Información contable en las entidades locales» Ed. ICAC. 1997.

José Pascual García: «Régimen Jurídico del Gasto Público». Ed. BOE. Madrid 1999.

A. Prospersi: «Manuale di contabilita e Bilanci degli enti locali». Il sole 24 ore. Milano 2001.

Rubio de Urquía y Arnal Suria: «La Ley de las Haciendas Locales». Ed. El Consultor. Madrid. 1996.

Ruiz HuerTa y otros: «Estructura y Gestión del Gasto en algunos países de la OCDE». IEF. 1993.

$F^{o}$ Sosa Wagner: «La Lealtad gozne del Estado». Rev. Estudios. $\mathrm{A}^{\circ}$ Local, n. ${ }^{\circ}$ 288. Enero-Abril 2002. Ed. INAP.

$\mathrm{F}^{\circ}$ Sosa WaGnEr: «La Autonomía Local» REALA, n. ${ }^{\circ} 239-240-241.1988$.

TORRES y PINA: «Public-Private partnership and private finance iniciatives in EU and Spanish local Governments». European Accounting Review. Nov. 2001.

B. TownLEY: «The cult of modernity». Financial Acountability \& Management. Nov. 2001.

P. VIRGA: «Diritto Amministrativo». Giuffre Ed. Milano. 1997. 